\title{
Quartzo e zircão como marcadores da evolução magmático- hidrotermal do Granito Antônio Vicente, Suíte Intrusiva Velho Guilherme, Província Carajás
}

\author{
Quartz And Zircon as markers of the magmatic-hydrothermal evolution of the Antônio \\ Vicente Granite, Velho Guilherme Intrusive Suite, Carajás Province

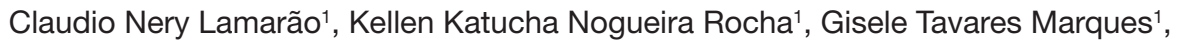 \\ Régis Munhoz Krás Borges ${ }^{1}$ \\ ${ }^{1}$ Instituto de Geociências, Universidade Federal do Pará - UFPA, Avenida Augusto Corrêa 1, CEP 66075-100, Belém, PA, BR \\ (lamarao@ufpa.br; kellenrocha@ufpa.br; gisageo15@yahoo.com.br; munhoz@ufpa.br )
}

Recebido em 17 de julho de 2012; aceito em 31 de janeiro de 2013

\begin{abstract}
Resumo
Quatro tipos morfológico-texturais de quartzo, informalmente denominados Qz1, Qz2, Qz3 e Qz4, foram identificados nas diferentes fácies do Granito Antônio Vicente, Província Carajás, por meio de imagens de microscopia eletrônica de varredura-catodoluminescência (MEV-CL). Nas rochas menos evoluídas, contendo anfibólio e biotita, dominam cristais anédricos a subédricos bem desenvolvidos, luminescentes e intensamente fraturados (Qz1). Fluidos hidrotermais que percolaram o granito transformaram o quartzo magmático (Qz1) em Qz2 e Qz3 por meio de processos de alteração, dissolução e recristalização, sendo essas transformações muito mais evidentes nas rochas sienograníticas intensamente alteradas. O Qz4 forma cristais médios a grossos, geralmente luminescentes e comparativamente pouco fraturados. Sua ocorrência é restrita às rochas sienograníticas fortemente hidrotermalizadas e aos corpos de greisens, sugerindo o início do processo de greisenização. Nos greisens, dominam cristais de quartzo euédricos médios a grossos, zonados concentricamente e com feições típicas de origem hidrotermal (Qz5). Finos cristais de cassiterita zonada ( $\leq 100 \mu \mathrm{m})$ são comuns e preenchem cavidades nos tipos Qz4 e Qz5. Zircões dominantemente anédricos, corroídos, com os mais elevados conteúdos de $\mathrm{Hf}$ e as mais baixas razões $\mathrm{Zr} / \mathrm{Hf}$, pertencem às rochas mais evoluídas e alteradas hidrotermalmente e aos corpos de greisens associados, ambos portadores de mineralizações de Sn. Tal fato sugere que a assinatura geoquímica do zircão, em especial a razão $\mathrm{Zr} / \mathrm{Hf}$, pode ser utilizada na avaliação preliminar do potencial metalogenético de granitos estaníferos.
\end{abstract}

Palavras-chave: MEV-catodoluminescência; Quartzo; Zircão; Greisens.

\begin{abstract}
Four morphological and textural types of quartz, informally labeled Qz1, Qz2, Qz3 and Qz4, were identified in the different facies of the Antônio Vicente Granite, Carajás Province, by scanning electron microscope-cathodoluminescence (SEM-CL) images. In the less evolved rocks, containing amphibole and biotite, well developed anhedral to subhedral, luminescent and intensely fractured crystals dominate, named Qz1. Hydrothermal fluids that percolated the granite modified the magmatic quartz (Qz1) into Qz2 and Qz3 through processes of alteration, dissolution and recrystallization, with these changes much more evident in the intensely altered syenogranite rocks. Qz4 constitute medium-to-coarse grained crystals, usually luminescent and comparatively little fractured. Its occurrence is restricted to strongly hydrotermalized syenogranite rocks and bodies of greisens, suggesting the beginning of the greisenization process. In the greisens, medium-to-coarse grained euhedral, concentrically zoned quartz crystals dominate, with typical features of hydrothermal origin (Qz5). Fine crystals of zoned cassiterite $(\leq 100 \mu \mathrm{m})$ are common and fill cavities in the types Qz4 and Qz5. Zircon crystals dominantly anhedral, corroded, with the highest contents of $\mathrm{Hf}$ and the lower $\mathrm{Zr} / \mathrm{Hf}$ ratios belong to more evolved and hydrothermally altered rocks and to associated greisens, both carriers of Sn mineralization. This fact suggests that the geochemical signature of zircon, especially $\mathrm{Zr} / \mathrm{Hf}$ ratio, can be used for the preliminary assessment of metallogenic potential of tin granites.
\end{abstract}

Keywords: SEM-cathodoluminescence; Quartz; Zircon; Greisens. 


\section{INTRODUÇÃO}

O Granito Antônio Vicente (GAV), situado aproximadamente a $50 \mathrm{~km}$ a noroeste da cidade de São Félix do Xingu, Província Carajás (Figura 1), é um dos corpos da Suíte Intrusiva Velho Guilherme mais bem estudados petrográfica, geoquímica e geocronologicamente (Teixeira e Dall'Agnol, 1991; Teixeira, 1999; Teixeira et al., 2002, 2005). É constituído por sienogranitos e monzogranitos hololeucocráticos a leucocráticos, com álcali-feldspato granitos subordinados, alterados em diferentes intensidades por processos tardi a pós-magmáticos. Mineralizações de Sn estão presentes nas rochas mais evoluídas e intensamente alteradas e em corpos de greisens associados.

O zoneamento composicional em minerais fornece um registro da história de cristalização e das condições envolvidas na formação das rochas ígneas (Loomis e Welber, 1982; Hogan, 1993; Slaby et al., 2008). Estudos recentes demonstram que o quartzo em rochas ígneas pode preservar zoneamentos capazes de fornecer informações importantes sobre sua história de cristalização (D'Lemos et al., 1997; Landtwing e Pettke, 2005; Müller, Seltaman, Behr, 2000; Müller, Kronz, Breiter, 2002; Müller et al., 2005). Esses zoneamentos e outras feições intracristalinas podem ser visualizados por meio de imagens de catodoluminescência (CL) obtidas com microscopia eletrônica de varredura (MEV). A CL é a luz emitida por uma amostra quando esta é excitada por um feixe de elétrons como, por exemplo, em um MEV. Ela é controlada por fatores como temperatura, estrutura cristalina, microfraturas, conteúdo de elementos traços, entre outros (Marshall, 1988). Por se tratar de uma metodologia eficaz, a CL tem sido utilizada para identificar diferentes gerações de quartzo de uma mesma unidade magmática (Müller et al., 2005), revelar padrões complexos de zoneamentos e defeitos intracristalinos, identificar estágios de deformação, caracterizar processos magmáticos envolvidos (por exemplo, mistura de magmas, reabsorção), auxiliar no estudo de evolução e cristalização de magmas, além de ser empregada na identificação e caracterização de quartzo hidrotermal (Rusk e Reed, 2002; Rusk, Lowers, Reed, 2008.; Larsen, Jacamon, Kronz, 2009). Além disso, o quartzo é capaz de incorporar certos elementos traços classificados como ativadores de $\mathrm{CL}$, por exemplo, Ti e Al, possibilitando informações quanto aos processos petrogenéticos e hidrotermais envolvidos na sua formação. Cristais de quartzo são, portanto, excelentes marcadores de processos magmáticos, metamórficos e sedimentares, sendo essas informações preservadas por suas heterogeneidades e zoneamentos composicionais internos (Boggs et al., 2001; Müller, Seltaman, Behr, 2000; Müller et al., 2003, 2005; Breiter, Forster, Skoda, 2005; Rusk, Lowers, Reed, 2008; Jacamon e Larsen, 2009; Larsen, Jacamon, Kronz, 2009).
Comparativamente, cristais de zircão mostram grande variação morfológica, textural e composicional que podem ser úteis para o entendimento de sua história de cristalização e de suas rochas hospedeiras. Zoneamentos composicionais em zircão marcam domínios geoquímicos distintos formados, provavelmente, em épocas diferentes. Tais zoneamentos comumente refletem variações nos conteúdos de $\mathrm{Zr}$ e Si, além de Hf, Y, Th, U, P e elementos terras raras (ETR) encontrados na sua estrutura (Heaman, Bowins, Crocket, 1990; Kempe et al., 1997, 2004; Uher et al., 1998; Hoskin e Ireland, 2000; Pupin, 2000; Wang et al., 2000; Belousova et al., 2002). A utilização de imagens de CL acompanhadas de análises químicas pontuais por EDS (Energy Dispersive Spectrometry), microssonda eletrônica ou LA-ICP-MS (Laser-ablation inductively coupled plasma mass spectrometry) têm sido empregadas para identificar variações composicionais em zircão magmático (Hanchar e Miller, 1993; Hanchar e Hudnick, 1995; Fowler et al., 2002), núcleos herdados, zoneamentos composicionais, bordas de sobrecrescimento (Paterson et al., 1992; Vavra et al., 1996; Wang, Griffin, Chen, 2010) e inclusões. Além disso, granitos especializados possuem zircões com enriquecimento significativo em $\mathrm{Hf}$ e baixas razões $\mathrm{Zr} / \mathrm{Hf}$, indicando que a composição desse mineral pode ser utilizada preliminarmente na prospecção de granitos mineralizados em Sn e metais associados (Wang et al., 2000; Kempe et al., 2004; Lamarão et al., 2007, 2010, 2012 e artigo em preparação).

Considerando que: (1) o principal processo responsável pela geração das diferentes fácies do GAV foi a cristalização fracionada (Teixeira, 1999), (2) este corpo foi afetado por intensas alterações tardi- a pós-magmáticas, (3) mineralizações de Sn estão presentes em suas rochas mais evoluídas e em corpos de greisens associados, e (4) quartzo e zircão podem fornecer informações importantes sobre a história de cristalização de seu magma gerador, este trabalho mostra as transformações morfológicas, texturais e composicionais de cristais de quartzo e zircão presentes nas diferentes fácies do GAV e em greisens associados por meio de imagens de MEV-CL e análises semiquantitativas de EDS.

\section{CONTEXTO GEOLÓGICO REGIONAL}

A região de São Félix do Xingu, situada nos domínios da Província Geocronológica Amazônia Central (Tassinari e Macambira, 2004), abrange rochas arqueanas representadas por unidades do Terreno Granito - Greenstone de Rio Maria - TGGRM (Costa et al., 1995) e do Supergrupo Itacaiúnas (Araújo et al., 1988). Dados petrográficos, geoquímicos e geocronológicos dividem os granitoides arqueanos do TGGRM em cinco principais grupos de rochas (Althoff, Barbey, Boullier, 2000; Leite et al., 2004; Almeida et al., 2008; Guimarães, 2009; Oliveira et al., 2009; 


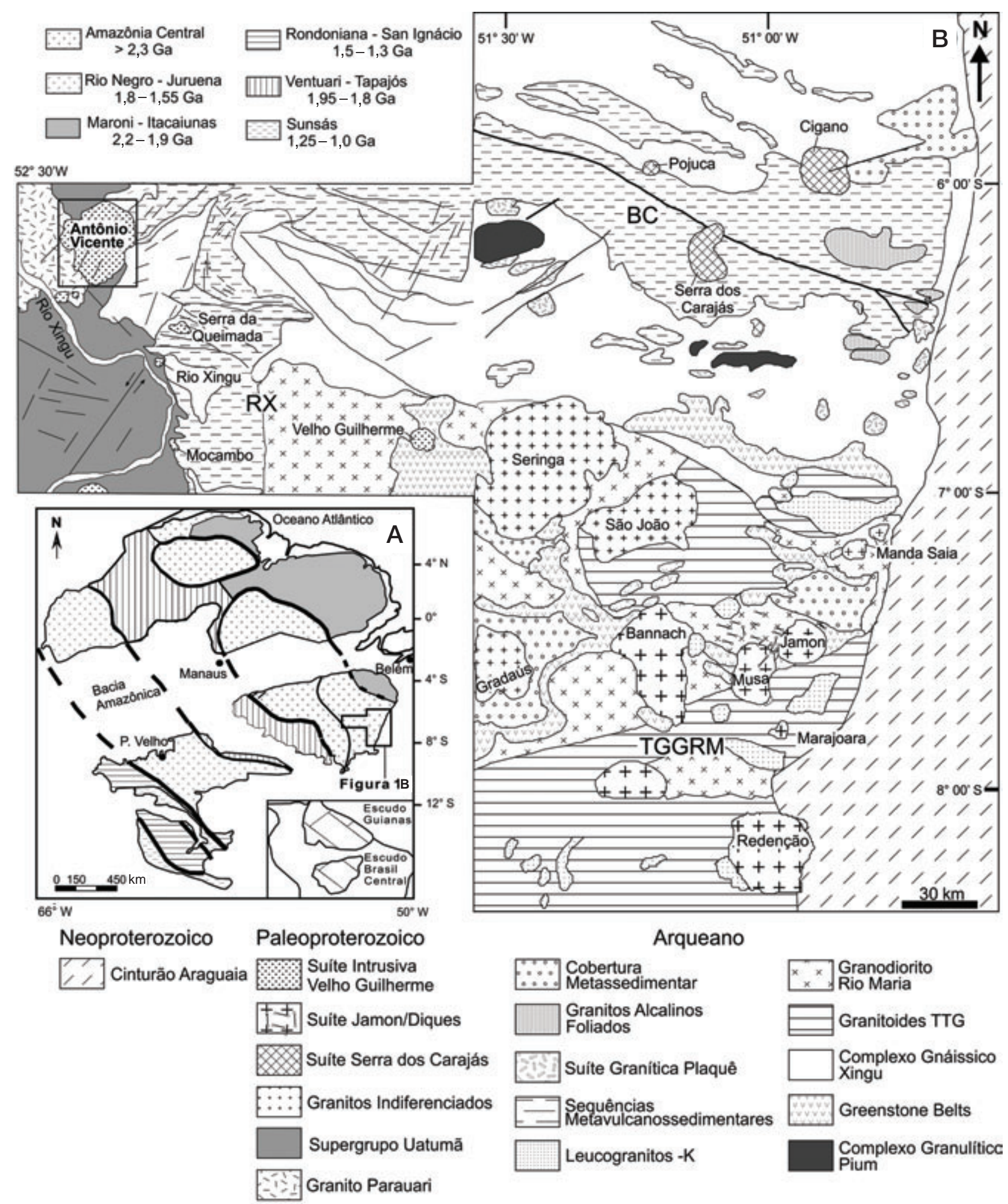

RX: Região do Xingu; TGGRM: Terreno Granito-Greenstone de Rio Maria; BC: Bacia Carajás. Baseado em Dall'Agnol et al. (2005).

Figura 1. (A) Esboço das Províncias Geocronológicas do Cráton Amazônico; (B) Mapa geológico simplificado da Província Mineral de Carajás com a localização do Granito Antônio Vicente. 
Almeida et al., 2010, 2011; Feio, 2011): 1) granitos da série tonalito-trondhjemito-granodiorito (TTG) antigos, representados pelo Tonalito Arco Verde e Trondhjemito Mogno $(2,96 \mathrm{Ga})$ e pelo Complexo Tonalítico Caracol e Tonalito Mariazinha (2,93 Ga); 2) granitos dominantemente granodioríticos com alto-Mg tipo sanukitoides (2,87 Ga), representados pelo Granodiorito Rio Maria e rochas máficas e intermediárias as sociadas; 3) leucogranodioritos e leucomonzogranitos cálcico-alcalinos com alto $\mathrm{Ba}$ e $\mathrm{Sr}$ representados pela Suíte Guarantã e similares $(2,87 \mathrm{Ga})$; 4) granitos TTG mais jovens representados pelo Trondhjemito Água Fria $(2,86 \mathrm{Ga})$, e 5) leucogranitos potássicos de afinidade cálcico-alcalina representados pelos granitos Xinguara, Mata Surrão (2,86 $2,87 \mathrm{Ga}$ ) e correlatos. As diversas unidades do TGGRM são cobertas parcialmente por rochas metassedimentares de idade arqueana do Grupo Rio Fresco (Huhn et al., 1988; Araújo et al., 1994) e cortadas por granitos anorogênicos paleoproterozoicos da Suíte Jamon (Dall'Agnol et al., 2005).

Nas proximidades de São Félix do Xingu, as rochas paleoproterozoicas são representadas por corpos máfico-ultramáficos da Suíte Cateté (Macambira e Ferreira Filho, 2002), pelo Granito Parauari (Macambira e Vale, 1997) e por vulcânicas das Formações Sobreiro e Iriri, do Grupo Uatumã (CPRM/DNPM, 1997; Fernandes, Lamarão, Teixeira, 2006; Pinho et al., 2006) ou Sobreiro e Santa Rosa (Fernandes, 2009; Juliani e Fernandes, 2010; Lagler, 2011). Além desses, vários maciços graníticos anorogênicos paleoproterozoicos com idades entre 1,88 - 1,86 Ga (Teixeira et al., 2002; Pinho, 2005) e portadores de mineralizações de Sn e W foram agrupados na Suíte Intrusiva Velho Guilherme - SIVG (CPRM/ DNPM, 1997; Teixeira et al., 1998, 2002) e constituem a Província Estanífera do Sul do Pará. Depósitos aluvionares quaternários compõem as unidades mais jovens da região.

A Figura 1A mostra um esboço do cráton Amazônico com a localização das Províncias Geocronológicas (Tassinari e Macambira, 2004), e a Figura 1B, o mapa geológico simplificado da Província Mineral de Carajás com a distribuição de granitos tipo A paleoproterozoicos das suítes Jamon, Serra dos Carajás e Velho Guilherme (Dall'Agnol et al., 2005), além dos granitos paleoproterozoicos indiferenciados Seringa, São João e Gradaús (Paiva Júnior, Lamarão, Lima, 2011).

\section{METODOLOGIA}

Foram estudadas 18 lâminas polidas (Tabela 1) representativas das diferentes fácies do GAV e greisens associados (Teixeira, 1999). O MEV utilizado foi o LEO-ZEISS 1430, do Instituto de Geociências da Universidade Federal do Pará - UFPA, com sistema de Mono-CL da Gatan e detector de EDS a seco SiriusSD acoplados. As lâminas polidas foram metalizadas durante 30 s com uma fina camada de platina. As condições de operação para obtenção de imagens de elétrons retroespalhados (ERE) e análises por EDS foram: corrente do feixe de elétrons $=90 \mu$ a, voltagem de aceleração constante $=20 \mathrm{kV}$, distância de trabalho $=15 \mathrm{~mm}$. As imagens de CL foram obtidas sob as mesmas condições, exceto a voltagem de aceleração, que foi de $10 \mathrm{kV}$, e a distância de trabalho, de $13 \mathrm{~mm}$. Análises semiquantitativas de EDS foram realizadas apenas nos cristais de zircão, uma vez que as concentrações de elementos traço no quartzo ficam muito abaixo dos limites de detecção do equipamento. As análises de EDS utilizaram o padrão $\mathrm{ZAF}\left(\mathrm{Z}=\mathrm{n}^{\mathrm{0}}\right.$ atômico, $\mathrm{A}=$ absorção atômica e $\mathrm{F}$ = fluorescência de Raios $\mathrm{X}$ ), que já vem instalado com o software e faz correções entre pico e background do elemento. O tempo de duração das análises de zircão foi de 30s, com 4.000 a 5.000 contagens/segundo para cada análise. Foram realizadas 450 análises situadas tanto nas bordas quanto no núcleo dos cristais, evitando-se, com a ajuda de imagens de ERE e CL, regiões de fraturas e proximidade de inclusões. Os elementos identificados foram $\mathrm{O}, \mathrm{Si}, \mathrm{Zr}, \mathrm{Hf}, \mathrm{Ce}$, $\mathrm{Nb}, \mathrm{Ta}, \mathrm{P}, \mathrm{Y}, \mathrm{Th}, \mathrm{U}, \mathrm{Ba}$ e Ca.

\section{EXEMPLOS DA APLICAÇÃO DE MICROSCOPIA ELETRÔNICA DE VARREDURA - CATODOLUMINESCÊNCIA EM QUARTZO E ZIRCÃO}

Imagens de MEV-CL são capazes de identificar feições texturais e gerações de quartzo distintas dentro de um mesmo grão, enquanto as análises químicas pontuais determinam a composição dos elementos traços presentes (D'Lemos et al., 1997; Müller, Seltaman, Behr, 2000; Müller, Kronz, Breiter, 2002; Müller et al., 2005; Chang e Meinert, 2004; Rusk et al., 2006; Rusk, Lowers, Reed,

Tabela 1. Relação das lâminas polidas utilizadas neste estudo com as respectivas fácies petrográficas do Granito Antônio Vicente (compilado de Teixeira, 1999).

\begin{tabular}{lccccc}
\hline BASMG & BMG & BSG & BSGA & BSGIA & Greisens \\
\hline NS-6 & GAM-CS-37 & SL-09-DT B & NE-B-82 & SL-02A-DT & NR-AV-26B \\
GFe-01 & GAM-CS-54 & NE-B-71 & NN-AV-BA4 & NE-B-83I & NN-AV-IN-10 \\
Bonsucesso & & SL-06C-DT & & NE-B-83 A & NN-AV-YN-16 \\
IE-02 & & & NE-B-75 & \\
\hline
\end{tabular}

BASMG: biotita-anfibólio sienogranito a monzogranito; BMG: biotita monzogranito; BSG: biotita sienogranito; BSGA: biotita sienogranito alterado; BSGIA: biotita sienogranito intensamente alterado. 
2008; Wiebe, Wark, Hawkins, 2007; Larsen, Jacamon, Kronz, 2009). Como esses elementos são altamente sensíveis a processos petrogenéticos, podem ser utilizados no reconhecimento da origem e evolução de rochas graníticas (Breiter e Müller, 2009; Jacamon e Larsen, 2009).

A Figura 2 mostra exemplos da aplicação de MEV-CL no estudo morfológico-textural de quartzo magmático e hidrotermal em diferentes localidades. Na Figura 2A, fenocristais de quartzo mostram núcleos cinza-escuros e zonas de crescimento oscilatório mais luminescente, indicando origem e história de crescimento similar (Müller et al., 2005). Nas Figuras 2B e 2C, fenocristais de quartzo subarredondados e zonados imersos em matriz felsítica, no Granito Vinalhaven, coastal Mine. A mudança abrupta entre núcleo escuro e bordas mais luminescentes em ambos os cristais indica modificação na composição. Neste caso, os núcleos escuros possuem entre 20 e 50 ppm de $\mathrm{Ti}$, enquanto as zonas mais luminescentes atingem até $140 \mathrm{ppm}$ de Ti (Wiebe, Wark, Hawkins, 2007). A Figura 2D mostra cristais de quartzo magmático primário luminescentes (Qz1), fraturados e alterados para Qz2 (cinza escuro), além de Qz3 intersticial e menos luminescentes que os anteriores (Larsen, Jacamon, Kronz, 2009). Na Figura 2E, veio de quartzo-molibdenita do depósito de cobre-pórfiro de Butte, Montana, Estados Unidos, mostra padrão textural em "teia de aranha", causado pela corrosão do quartzo ao longo de intensa rede de microfraturas (Rusk e Reed, 2002). Na Figura 2F, dois tipos de quartzo podem ser individualizados em veio de quartzo contendo pirita (Py) e sericita (Ser): núcleos de quartzo embaiados e luminescentes (Qz1), cercados por cristais euédricos cinza-escuros de quartzo hidrotermal (Qz2). Esse tipo de textura é interpretado como causado pela precipitação do quartzo luminescente, seguido de dissolução e posterior precipitação do quartzo cinza a partir de fluidos quimicamente distintos a temperatura e pressão mais baixas (Rusk e Reed, 2002).

Cristais de zircão de diferentes unidades litológicas podem apresentar morfologia e zoneamentos composicionais
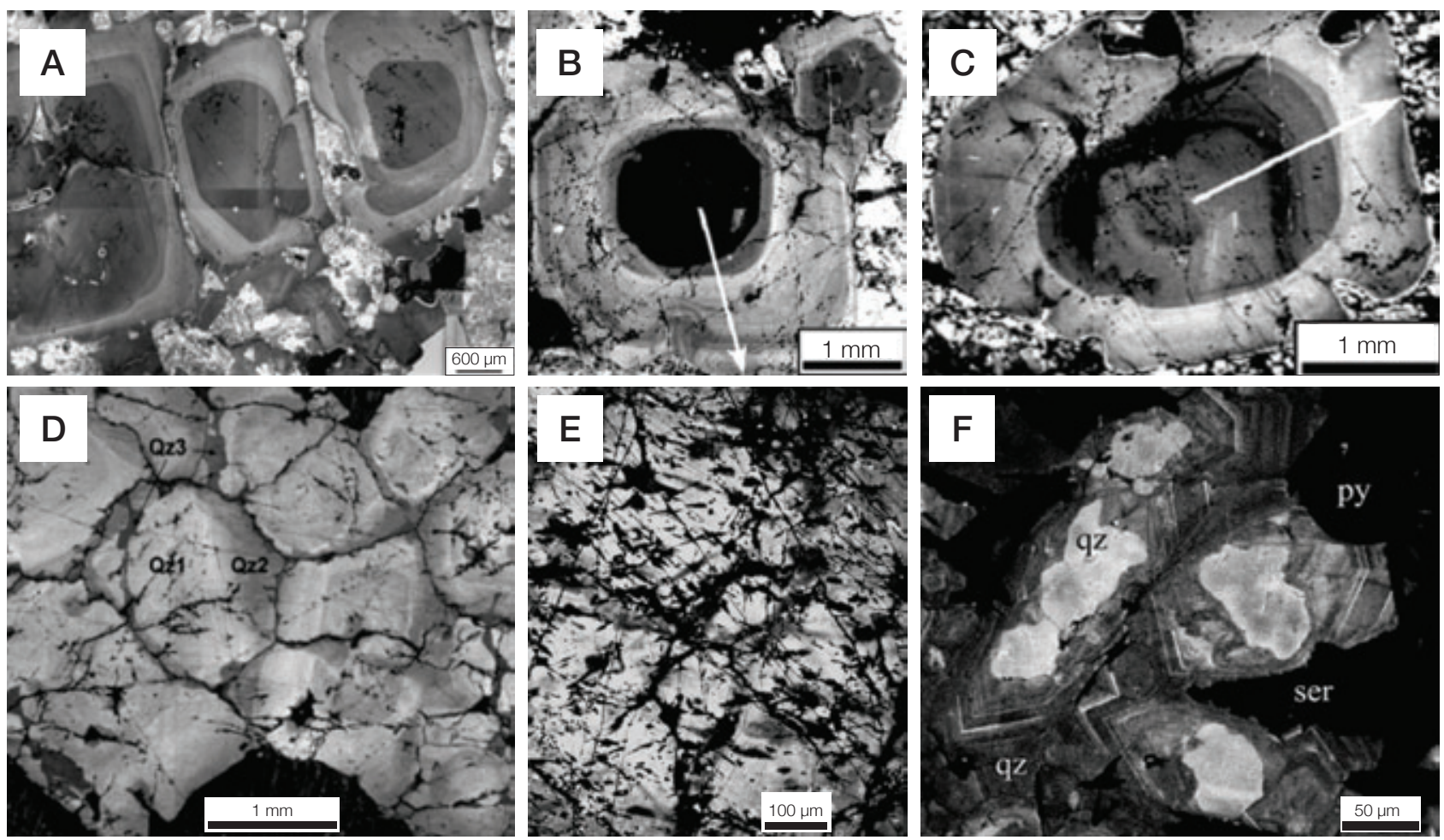

py: pirita; ser: sericita

Figura 2. Imagens de microscopia eletrônica de varredura - catodoluminescência (MEV - CL) de cristais de quartzo. (A) Fenocristais com núcleos cinza-escuros e zonas de crescimento oscilatório mais luminescente, sugerindo origem e história de crescimento similares - Granito Schellerhau, Complexo vulcano-plutônico de Erzgebirge, Alemanha (Müller et al., 2005); (B-C) Cristais subarredondados e fortemente zonados com núcleos escuros e bordas luminescentes, Granito Vinalhaven, coastal Mine. As setas indicam aumento das concentrações de Ti (Wiebe, Wark, Hawkins, 2007); (D) Cristais de quartzo magmático primário (Qz1), luminescentes e alterados para quartzo cinza escuro (Qz2); quartzo mais escuro (Qz3) desenvolve-se intersticialmente - granito do Rift Continental de Oslo, Noruega (Larsen, Jacamon, Kronz, 2009); (E) Veio de quartzo-molibdenita do depósito de cobre-pórfiro de Butte, Montana, mostrando intensa rede de microfraturas e padrão textural em "teia de aranha" (Rusk e Reed, 2002); (F) Núcleos de quartzo (qz) embaiados e luminescentes, cercados por cristais euédricos cinza-escuros de quartzo hidrotermal. (Rusk e Reed, 2002). 
distintos quando observados em CL. A Figura 3 compara cristais de zircão de rochas traquíticas das Formações Vila Riozinho (FVR) e Moraes Almeida (FMA), Província Aurífera do Tapajós (Lamarão e Marques, em preparação), com idades de 2,0 e 1,88 Ga, respectivamente (Lamarão et al., 2002; Lamarão, Dall'Agnol, Pimentel, 2005). Os zircões da FVR são dominantemente euédricos, possuem núcleos euédricos a subédricos escuros (Figuras 3A e 3B) a cinza claro (Figuras $3 \mathrm{C}$ e $3 \mathrm{D}$ ) circundados por zonas de crescimento com contrastes na espessura e/ou luminescência. Tais zonas mostram-se frequentemente truncadas por descontinuidades (zonas escuras), as quais podem representar períodos de reabsorção e/ou dissolução (Hoffman, 2007). Entretanto, os cristais apresentam crescimento cíclico, com alternância de zonas claras mais desenvolvidas e zonas escuras comparativamente mais finas, denotando variações composicionais durante a cristalização. Finas inclusões $(\leq 20 \mu \mathrm{m})$ anédricas luminescentes de apatita e, mais raramente, álcali-feldspato, são comuns (Figuras 3A e 3D). Por outro lado, zircões de traquito da FMA (Figuras 3E e 3H) mostram feições internas comparativamente distintas. Apresentam núcleos euédricos bem desenvolvidos em tons cinza pouco luminescentes e textura interna uniforme, sugerindo longos períodos de crescimento com variações composicionais imperceptíveis ou pouco pronunciadas. Tais núcleos são circundados por zonas de crescimento luminescentes. Cristais de zircão com esse padrão de zoneamento não foram observados nos traquitos da FVR.

\section{GRANITO ANTÔNIO VICENTE}

\section{Aspectos petrológicos}

O GAV possui forma subcircular e é intrusivo a norte e nordeste em rochas do Complexo Xingu, do Grupo São Sebastião e da Formação Sobreiro (Grupo Uatumã). A sudeste e a sul, corta rochas das Formações Sobreiro e Iriri (Grupo Uatumã), e a oeste e noroeste, do Granito Parauarí (Teixeira, 1999; Teixeira et al., 2002). Quatro domínios petrográficos foram identificados (Teixeira e Dall'Agnol, 1991; Teixeira, 1999): (1) biotita-anfibólio sienogranito a monzogranito (BASMG) pouco afetado por alterações tardi- a pós-magmáticas; (2) anfibólio-biotita
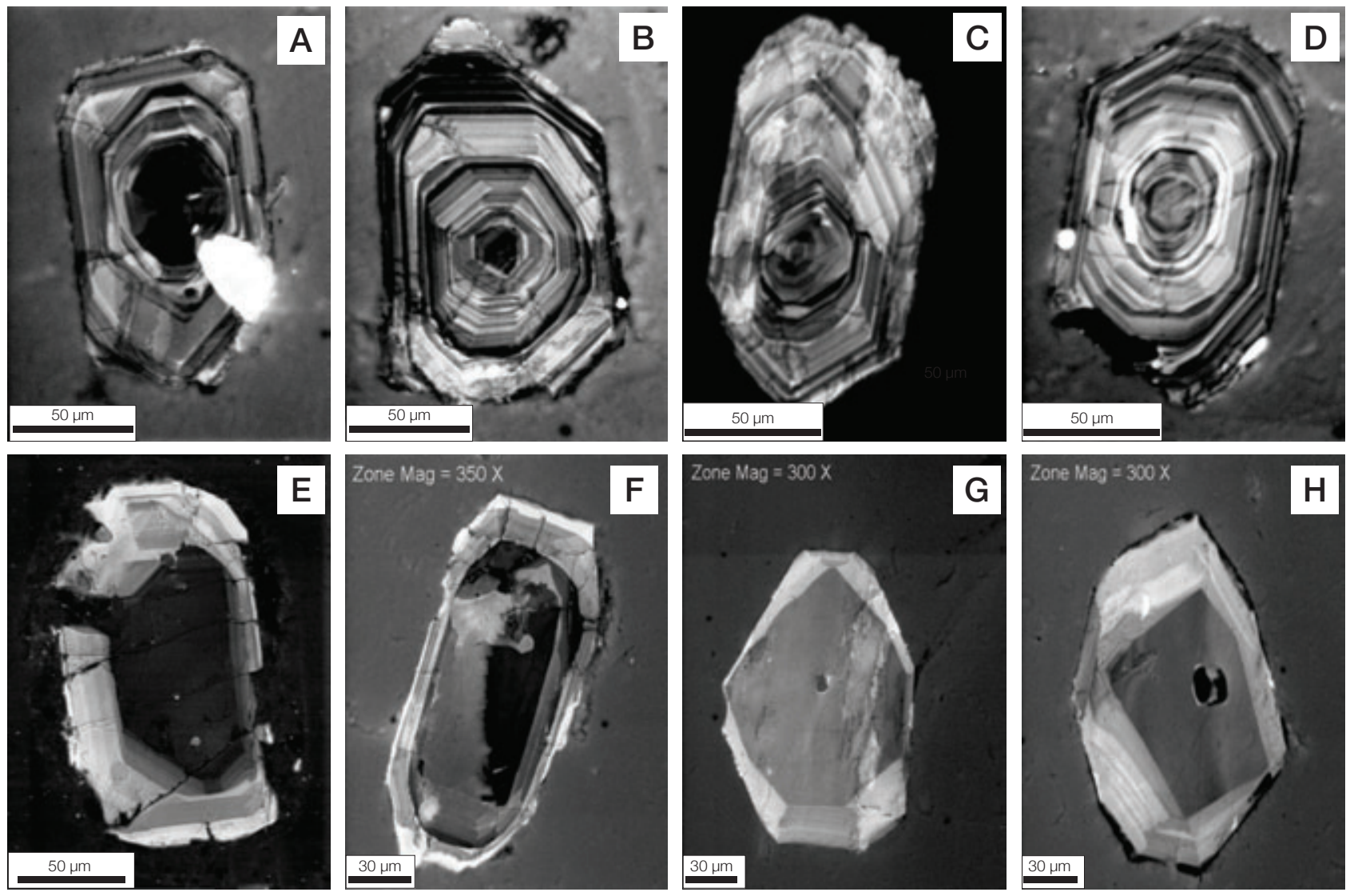

Figura 3. Imagens de microscopia eletrônica de varredura - catodoluminescência (MEV - CL) de cristais de zircão de traquitos das Formações Vila Riozinho $(A-D)$ e Moraes Almeida $(E-H)$. Nota-se diferença marcante nos tipos de zoneamentos composicionais entre zircões das duas unidades litológicas. 
sienogranito (ABSG); (3) biotita monzogranito (BMG) e, (4) biotita sienogranito (BSG), com ocorrência de tipos alterados (BSGA) e intensamente alterados (BSGIA).

Os BASMG apresentam textura hipidiomórfica heterogranular média a grossa, coloração cinza escura a rosa acinzentado e conteúdo de máficos entre 5 e $15 \%$. Magnetita, ilmenita, apatita, titanita, allanita e zircão são as principais fases acessórias. As fases secundárias estão representadas por sericita-muscovita \pm clorita \pm fluorita, epidoto \pm carbonato e pela albitização dos feldspatos potássicos e, subordinadamente, do plagioclásio primário (Teixeira et al., 2002). Os BMG possuem textura hipidiomórfica, granulação fina a grossa e coloração rosa esbranquiçada a rosa acinzentada. Zircão, magnetita, ilmenita e apatita são os principais acessórios e clorita o principal máfico secundário. Os minerais secundários estão representados por sericita \pm muscovita \pm clorita \pm fluorita \pm epidoto \pm topázio, microclina pertítica, albita, calcopirita, esfalerita, thorita, xenotímio, monazita e argilominerais. A cassiterita está associada a esse estágio e ocorre preferencialmente nos BSGIA.

Os greisens formam corpos tabulares alojados em fraturas e/ou falhas nos BSG. Três tipos foram identificados: muscovita-quartzo greisen (MQG), quartzo-clorita greisen (QCG) e clorita-siderofilita-muscovita-quartzo greisen (CSMQG). Para este estudo, foram utilizados cristais de quartzo e zircão do MQG (amostra NR-AV-26B) e CSMQG (amostras NNAV-IN-10 e NN-AV-YN-16).

Geoquimicamente, o GAV mostra natureza subalcalina, caráter metaluminoso a levemente peraluminoso, assinatura de granitos tipo-A (Whalen, Currie, Chappell, 1987) e afinidade geotectônica com granitos intraplaca (Pearce, Harris, Tindle, 1984). Segundo Teixeira e Bettencourt (2000), a cristalização fracionada foi o principal processo petrogenético que governou a evolução desse corpo. As Figuras 4 e 5 mostram, respectivamente, o mapa geológico do GAV com suas principais fácies petrográficas e feições mineralógicas

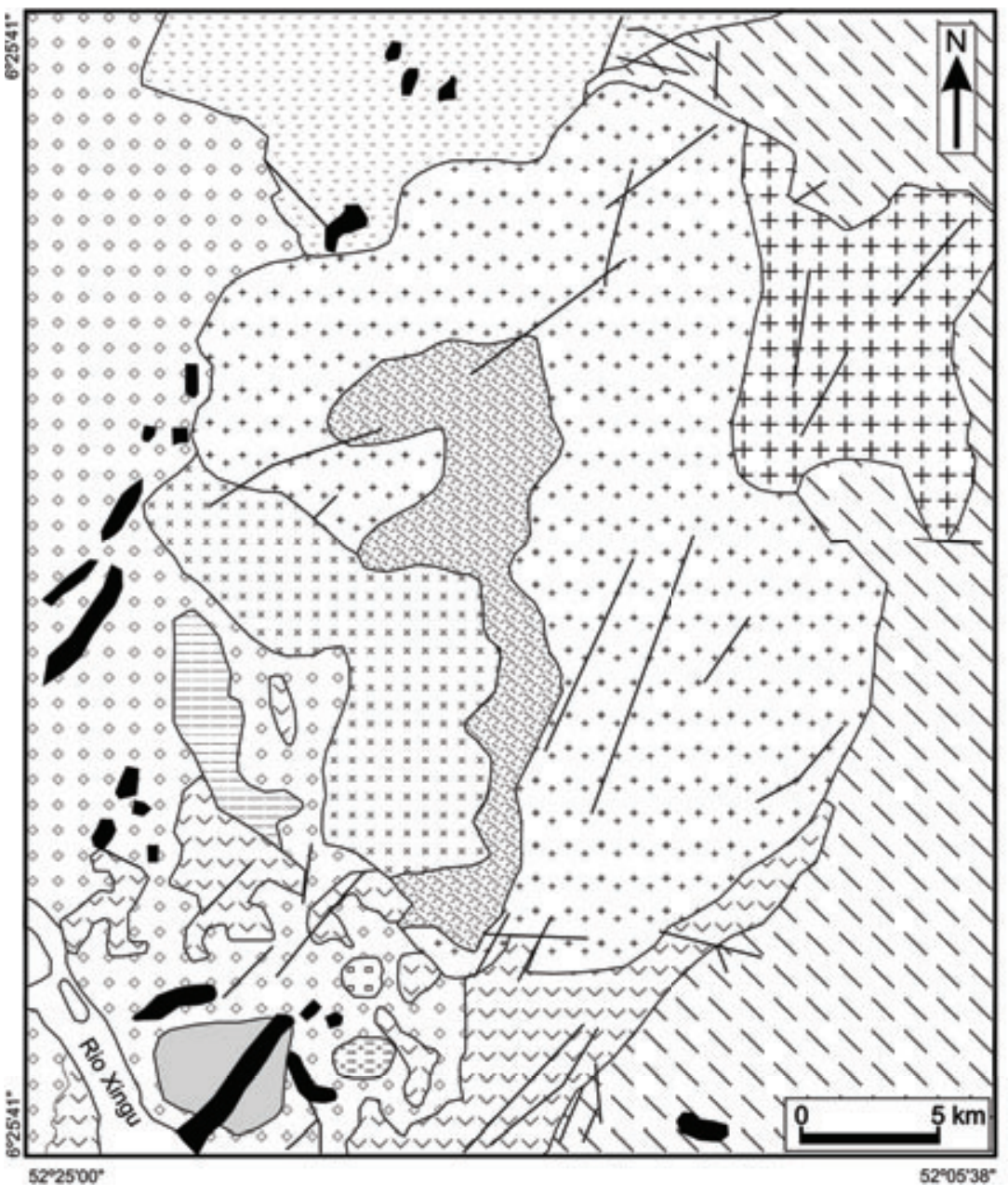

DIABASIO CURURU

SUITE INTRUSIVA VELHO GUILHERME

\begin{tabular}{l}
\hline Maciço Granitico Benedita \\
Maciço Granitico Ubim Norte \\
Maciço Granitico Ubim Sul
\end{tabular}

Maciço Granítico Antônio Vicente

FKSXX Biotita-anfibólio sienogranito a monzogranito rico em máficos.

Anfibólio-biotita sienogranito,

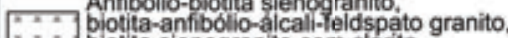
biotita sienogranito con clorita, álcali-feldsspato granito.

Biotita sienogranito com biotita monzogranito subordinado pouco a intensamente alterado ++7 Biotita monzogranito com biotita sienogranita subordinado.

\section{FORMAÇĀO TRIUNFO}

ZU GRUPO UATUMÃ

$\because$ GRANITO PARAUARI

$\triangle$ SEQUENCIAS E GRANITOIDES ARQUEANOS INDIFERENCIADOS

\section{$\int$ Contato geológico fotointerpretado \\ Falhas e/ou fraturas fotointerpretadas indiscriminadas}

Figura 4. Mapa geológico do Granito Antônio Vicente mostrando suas principais fácies petrográficas (modificado de Teixeira e Dall'Agnol, 1991). 
e texturais de cada uma delas. Na Tabela 2, são listadas as principais características petrográficas identificadas nas rochas do GAV e em um corpo de greisen associado (modificado de Teixeira, Bello, Bettencourt, 2002).

\section{Estudos de quartzo do Granito Antônio Vicente}

\section{Comparação entre imagens de quartzo obtidas por microscopia eletrônica de varredura}

A Figura 6 compara imagens de ERE e CL de cristais de quartzo do GAV e mostra a eficiência da CL para estudos morfológicos e texturais de quartzo. Fraturas seladas, preenchidas por quartzo preto tardio, são observadas apenas em imagens de CL (Figuras 6A, 6B, 6E e 6F), enquanto fraturas abertas podem ser vistas em ambos os tipos de imagens. Cristal com núcleo luminescente e zonas composicionais claro-escuras alternadas pode ser identificado em imagem de CL (Figura 6D). A alteração do quartzo magmático luminescente para quartzo secundário cinza é evidente em CL, assim como a presença de quartzo preto preenchendo microfraturas e seccionando os tipos anteriores.

\section{Tipos de quartzo identificados por microscopia eletrônica de varredura - catodoluminescência}

Com base em feições morfológico-texturais e em trabalhos da literatura, foi possível distinguir quatro principais gerações de quartzo nas rochas do GAV e uma em greisens associados aos BSGIA (Figura 7):

- Qz1, considerado o tipo mais precoce ocorre em todas as fácies e, raramente, nos greisens. Forma cristais anédricos a subédricos luminescentes, intensamente fraturados (Figura 7A), por vezes com núcleos luminescentes envoltos por mantos claro-escuros concentricamente alternados (Figura 6D), indicando mudanças efetivas na composição do magma. Esse zoneamento oscilatório confere origem magmática primária ao cristal (Müller et al., 2003; Wiebe, Wark, Hawkins, 2007; Larsen, Jacamon, Kronz, 2009).
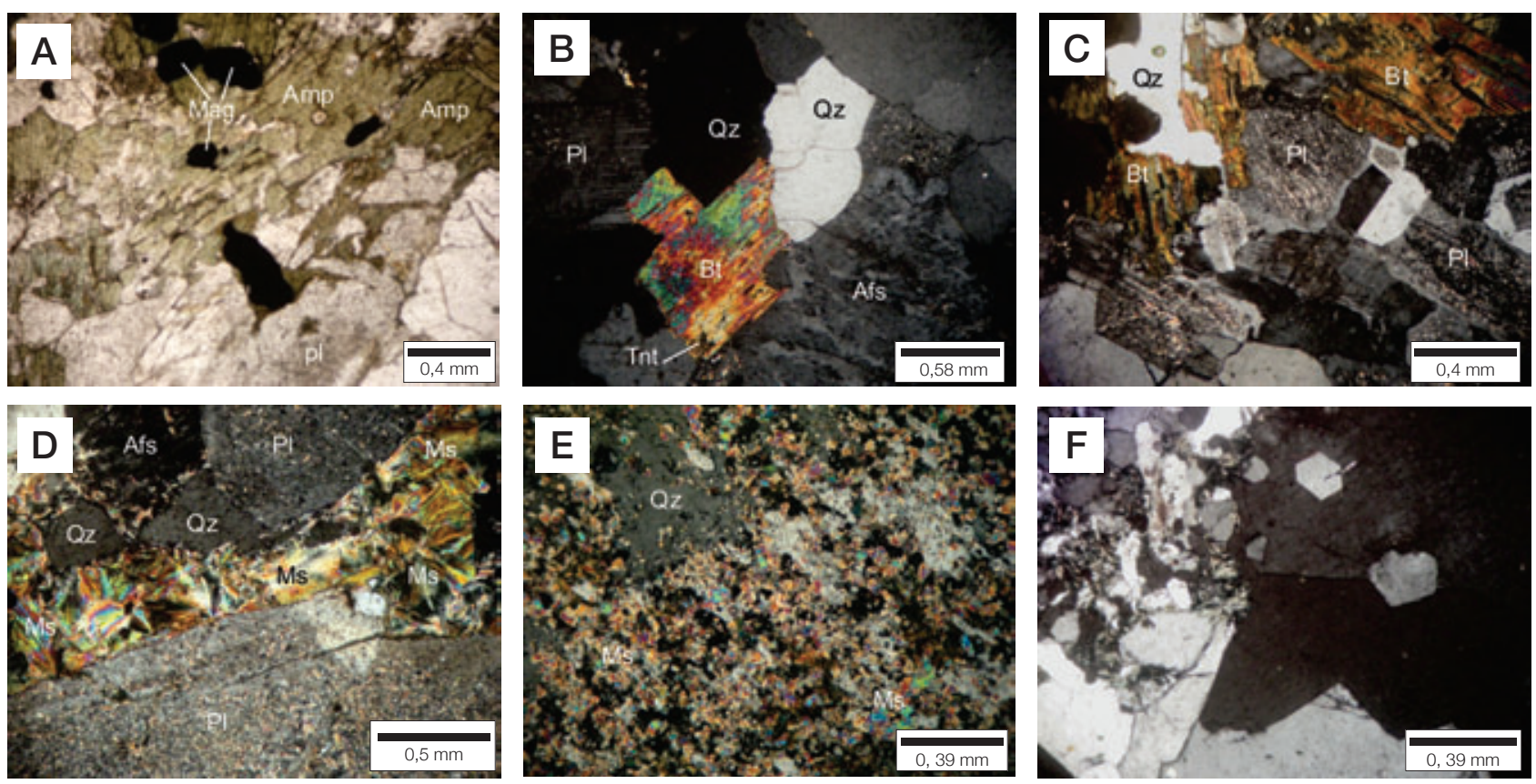

Figura 5. Feições mineralógico-texturais das diferentes rochas do Granito Antônio Vicente e de greisens associados. (A) Biotita-anfibólio sienogranito a monzogranito (BASMG). Cristais de anfibólio (Amp) verde-claro parcialmente corroídos contendo inclusões de magnetita (Mag) entre cristais sericitizados de plagioclásio (PI); (B) Biotita monzogranito (BMG). Cristal de biotita (Bt) parcialmente corroído e alterado para titanita (Ttn) e óxido de ferro ao longo das clivagens; quartzo (Qz), álcalifeldspato (Afs) pertítico e plagioclásio sericitizado aparecem associados; (C) Biotita sienogranito alterado (BSGA). Cristais corroídos e alterados de biotita ocorrem dispersos entre cristais de plagioclásio sericitizados, álcali-feldspato argilizados e quartzo; (D) Biotita sienogranito intensamente alterado (BSGIA). Detalhe de cristais de plagioclásio intensamente sericitizados, quartzo e álcali-feldspato pertítico com ocorrência de agregado de muscovita (Ms); (E) Greisen NN-AV-IN-10. Detalhe da grande quantidade de muscovita associada a cristais anédricos de quartzo; (F) Greisen NR-AV-26B. Cristais de quartzo com faces retas contendo finas inclusões de quartzo euédricos, todos identificados como quartzo hidrotermal (Qz5). Em (A), tem-se nicóis paralelos. Em (B-F) tem-se nicóis cruzados. Abreviações segundo Whitney e Evans (2010). 
- Qz2, pouco luminescente, forma bordas de espessuras variáveis ou manchas irregulares descontínuas cinza a cinza escuras no Qz1 (Figura 7B). É comum também preenchendo microfraturas no Qz1.

- Qz3 apresenta cor preta e preenche microfraturas, seccionando os dois tipos anteriores (Figura 7C). Está presente em todas as fácies, porém é raro nos greisens. Os tipos Qz2 e Qz3 foram gerados tardiamente em relação ao Qz1 em decorrência, muito provavelmente, de reações entre este e os fluidos hidrotermais que afetaram o GAV (Larsen, Jacamon, Kronz, 2009).

- Qz4, identificado apenas nas rochas mais intensamente hidrotermalizadas (BSGIA) e greisens, forma cristais anédricos isentos ou pouco fraturados quando comparados aos tipos anteriores (Figura 7D). Apresenta luminescência variável, desde tons brilhosos até cinza escuro.

- Qz5, dominante nos greisens ou preenchendo cavidades nas rochas mais evoluídas (Figuras 7E e 7F), forma cristais euédricos médios a grossos pouco fraturados, por vezes finos agregados de cristais. Mostra zoneamentos claro-escuro bem definidos em um padrão tipicamente hidrotermal (Rusk e Reed, 2002; Rusk, Lowers, Reed, 2008).

\section{Evolução morfológica e textural}

O estudo de MEV-CL mostrou que o quartzo magmático (Qz1), presente em todas as fácies do GAV, sofreu modificações progressivas pelos fluídos hidrotermais que percolaram e alteraram o granito, transformando-o em Qz2 e Qz3 hidrotermais. Tais modificações são mais intensas do BASMG para o BSGIA, ou seja, com o avanço da cristalização fracionada. Como as rochas mais evoluídas são também as mais intensamente alteradas, cristais de quartzo presentes nessas rochas registraram tais modificações sob a forma de alteração, dissolução e recristalização.

A Figura 8 mostra imagens de MEV-CL de cristais de quartzo dispostas no sentido das rochas menos evoluídas

Tabela 2. Características petrográficas das principais fácies graníticas e de greisen do Granito Antônio Vicente (modificado de Teixeira, Bello, Bettencourt, 2002).

\begin{tabular}{|c|c|c|c|c|c|c|}
\hline $\begin{array}{l}\text { Fácies } \\
\text { graníticas }\end{array}$ & $\begin{array}{c}\text { Minerais } \\
\text { essenciais } \\
\text { (\% modal) }\end{array}$ & $\begin{array}{c}\text { Minerais varietais } \\
\text { (\% modal) }\end{array}$ & $\begin{array}{c}\text { Minerais } \\
\text { acessórios } \\
\text { primários }\end{array}$ & $\begin{array}{l}\text { Minerais } \\
\text { secundários }\end{array}$ & $\begin{array}{c}\text { Estilo de } \\
\text { mineralização }\end{array}$ & $\begin{array}{c}\text { Associação } \\
\text { mineral } \\
\text { correlata }\end{array}$ \\
\hline BASMG & $\begin{array}{c}\text { Qz }(22-38) \\
\text { PI (Ab/Olig-And) } \\
(13-44) \\
\text { K-fsp }(20-53)\end{array}$ & $\begin{array}{c}\mathrm{Al}-\mathrm{Hs} / \mathrm{Fe}-\mathrm{Ed} \\
(2-13) \\
\mathrm{Bt}(<1-6)\end{array}$ & $\begin{array}{l}\text { Mag, IIm Ap, Ttn, } \\
\text { Zrn, Aln }\end{array}$ & $\begin{array}{c}\text { Ser, Ms, Chl, Ep, } \\
\text { Fl, Cb, K-Fsp, } \\
\text { Ab, Opq, Qz, } \\
\text { Argilominerais. }\end{array}$ & Ausente & Ausente \\
\hline$B S G$ & $\begin{array}{c}\text { Qz }(21-51) \\
\text { PI (Ab/Olig) } \\
(9-29) \\
\text { K-fsp (21-60) }\end{array}$ & $\mathrm{Bt}(<1-12)$ & Ilm, Ccp, Ap, Zrn & $\begin{array}{c}\text { Ser, Ms, Chl, Ep, } \\
\text { Fl, K-Fsp, } \\
\text { Ab, Tpz, Aln, Mnz, } \\
\text { Ilm, Qz, } \\
\text { argilominerais. }\end{array}$ & Ausente & Ausente \\
\hline BSGIA & $\begin{array}{c}\text { Qz }(25-44) \\
\text { PI (Ab/Olig) } \\
(10-28) \\
\text { K-fsp (23 - 49) }\end{array}$ & $\mathrm{Bt}(<1-2)$ & $\begin{array}{c}\| \mathrm{m}, \mathrm{Ccp}, \mathrm{Xtm}, \mathrm{Ap}, \\
\text { Zrn }\end{array}$ & $\begin{array}{l}\text { Ser, Ms, Chl, Ep, } \\
\text { Fl, K-Fsp, Ab, } \\
\text { Tpz, Cst, Ilm, Sp, } \\
\text { Qz, argilominerais. }\end{array}$ & $\begin{array}{l}\text { Disseminada } \\
\text { Veios }\end{array}$ & $\begin{array}{c}\text { Cst, Fl, Tpz } \\
\text { FI }\end{array}$ \\
\hline $\begin{array}{l}\text { Greisen } \\
\text { CSMQGs }\end{array}$ & $\begin{array}{l}\text { Qz }(56-62) \\
\text { Ms }(13-17) \\
\text { Siderofilita } \\
(12-17) \\
\text { Chl }(3-12)\end{array}$ & & Bt, Zrn, Thr, Sp & Mnz, Fl, Tpz, Cst & Disseminada & Cst, Fl, Tpz \\
\hline
\end{tabular}

Qz: quartzo; Pl: plagioclásio; Ab: albita; Olig: oligoclásio; And: andesina; K-fsp: feldspato potássico; Ms: muscovita; Chl: clorita; Al: alumínio; Hs: hastingsita; Bt: biotita; Mag: magnetita; IIm: ilmenita; Ccp: calcopirita; Xtm: xenotímio; Sp: esfalerita; Ap: apatita; Ttn: titanita; Zrn: zircão; Aln: allanita; Ser: sericita; Ep: epidoto; FI: fluorita; Cb: carbonato; Tpz: topázio; Mnz: monazita; Cst: cassiterita. CSMQGs: clorita-siderofilita-muscovita-quartzo greisen. Abreviações segundo Whitney e Evans (2010). 

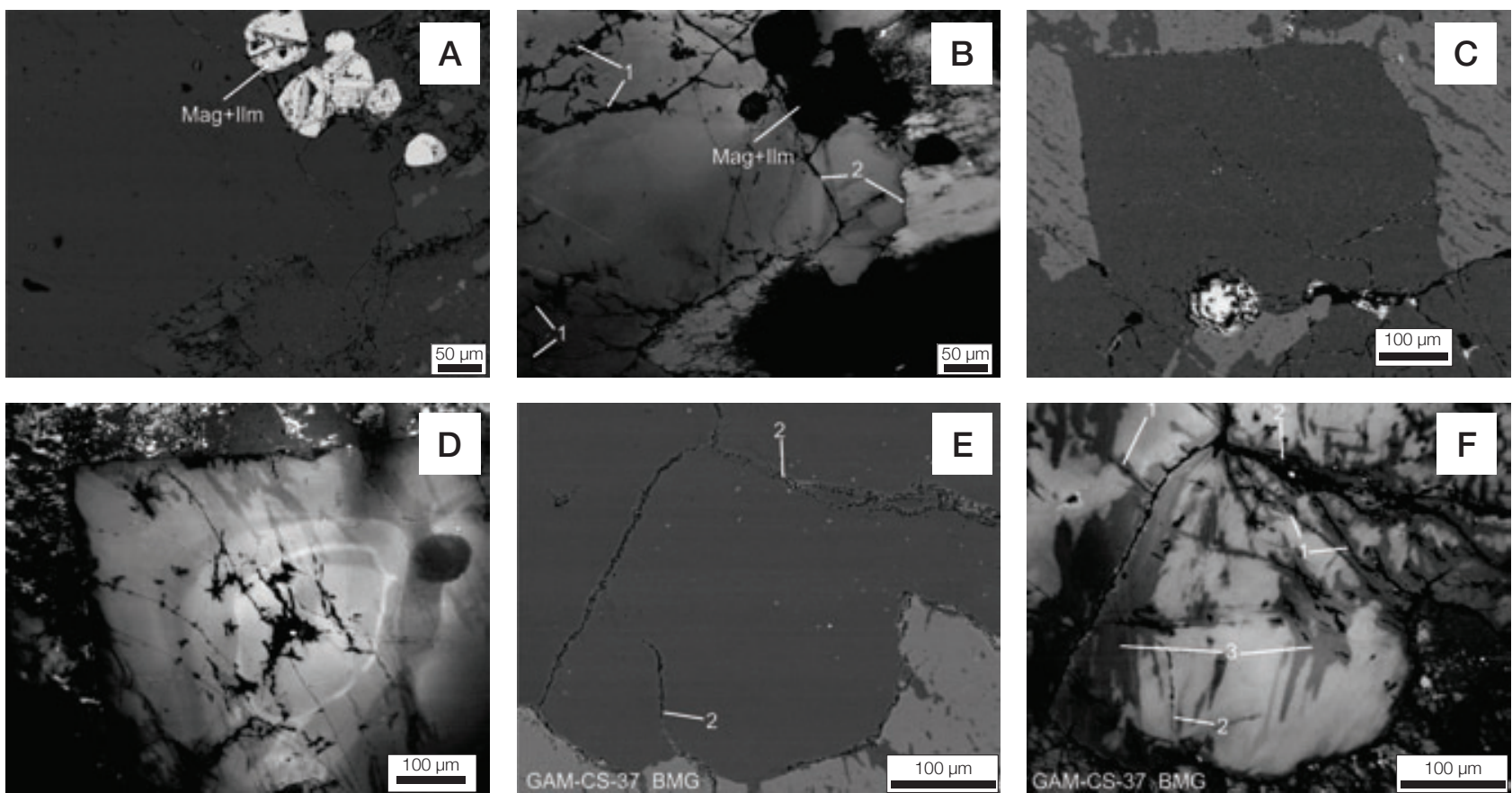

1: fraturas preenchidas por quartzo tardio visíveis apenas em CL; 2: fraturas abertas visíveis em ERE e CL ( $\mathrm{A}, \mathrm{B}, \mathrm{E}, \mathrm{F})$; 3: quartzo secundário (cinza escuro) desenvolvendo-se ao longo de fraturas sobre o quartzo primário mais luminescente $(\mathrm{F})$.

Mag + IIm: inclusões de magnetita + ilmenita em treliça no contato entre cristais de quartzo e álcali-feldspato. Em D, núcleo luminescente, contendo fraturas preenchidas por quartzo tardio (preto), envolto por zonas composicionais mais escuras, imperceptíveis em imagens de ERE (C).

Figura 6. Imagens de cristais de quartzo do Granito Antônio Vicente obtidas por microscopia eletrônica de varredura elétrons retroespalhados (MEV-ERE) (A, C, E) e catodoluminescência (CL) (B, D, F).
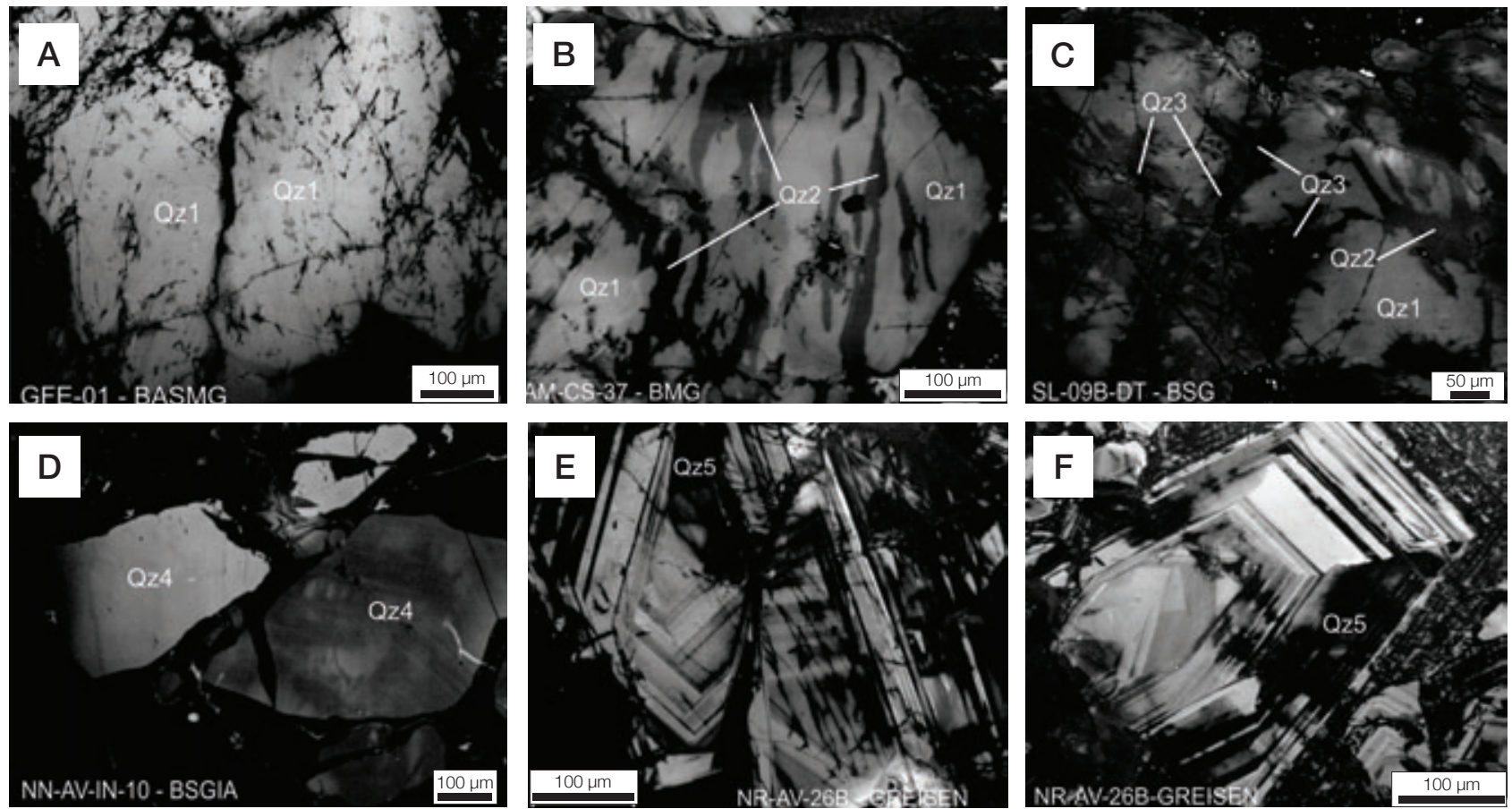

Qz1: magmático e luminescente; Qz2: cinza escuro, pouco luminescente; Qz3: preto, preenche fraturas e secciona os tipos anteriores; Qz4: anédrico, pouco fraturado, com luminescência variável; Qz5: euédrico, zonado e tipicamente hidrotermal. BASMG: biotita-anfibólio sienogranito a monzogranito; BMG: biotita monzogranito; BSG: biotita sienogranito; BSGIA: biotita sienogranito intensamente alterado.

Figura 7. (A-F) tipos de quartzo identificados nas rochas do Granito Antônio Vicente e greisens associados através de imagens de microscopia eletrônica de varredura - catodoluminescência (MEV - CL). 
(BASMG) para as mais evoluídas e alteradas hidrotermalmente (BSGIA), seguidas de imagens de quartzo de greisens associados a essas últimas. A sequência de imagens demonstra que o quartzo do GAV foi um bom marcador das alterações impostas pelos processos tardi- a pós-magmáticos que atuaram no corpo como um todo. De um modo geral, o quartzo primário (Qz1) está presente em todas as fácies, porém encontra-se mais preservado nas rochas menos evoluídas (BASMG a BMG). Neste caso, forma cristais bem desenvolvidos, luminescentes e intensamente fraturados (Figuras 8A e 8B). Entretanto, alguns cristais de Qz1 do BASMG estão alterados para Qz2 e Qz3, evidenciando que as transformações no GAV ocorreram de forma generalizada, embora mais intensas nos BSG. Cristais de Qz1 com zoneamentos composicionais que atestam sua origem magmática (Müller, Seltaman, Behr, 2000) são comuns nessas rochas (Figura 6D).

Na passagem dos BMG para os BSG, os processos hidrotermais foram mais intensos e promoveram a alteração do Qz1 para Qz2 na forma de manchas cinza irregulares e pouco luminescentes, como mantos cinza bordejando os cristais de Qz1 ou, ainda, aproveitando a rede de fraturas já existente (Figuras 8C a 8F). Nos BSGA e BSGIA, a formação de Qz2 é dominante, deixando pequenas "ilhas" remanescentes de Qz1 (Figuras 8G e 8H). O Qz3, de cor preta, preenche fraturas e secciona os tipos anteriores (Figuras 8C a $8 \mathrm{H}$ ), sendo, portanto, posterior. Nos BSGIA e greisens associados, aparecem cristais de quartzo médios a grossos, geralmente luminescentes e comparativamente pouco fraturados, denominados de Qz4. Esse tipo de quartzo, não identificado nas outras rochas do GAV, parece marcar o início do processo de greisenização (Figuras 8I a 8J).

Por outro lado, nos greisens foram identificados finos agregados de quartzo euédricos (Figura 8J) ou cristais médios a grossos com zoneamentos concêntricos claro-escuros bem definidos, comumente preenchendo cavidades (Figuras 8K e 8L). Tais cristais mostram feições morfológicas e texturais típicas de origem hidrotermal (Rusk e Reed, 2002; Rusk, Lowers, Reed, 2008) e foram designados de Qz5. Cristais anédricos de cassiterita zonada, geralmente inferiores a $100 \mu \mathrm{m}$, são comuns preenchendo cavidades neste tipo de quartzo ou associadas ao Qz4 (Figura 9).

\section{Estudo de zircão do Granito Antônio Vicente}

A Tabela 3 apresenta dados químicos semiquantitativos médios de cristais de zircão das rochas do GAV e de greisens associados, e a Figura 10 mostra a evolução morfológica desses zircões com seus conteúdos variáveis de Hf e Y.

Em linhas gerais, os zircões dos BASMG são euédricos a subédricos, pouco fraturados e corroídos, com conteúdos médios de $\mathrm{Hf}$ e $\mathrm{Y}$ de 1,9 e 0,8\%, respectivamente. Nos $\mathrm{BMG}$, cristais subédricos e levemente mais enriquecidos em
Hf (média de 2,2\%) passam a ser dominantes. Nos zircões dos BSGA, é comum a presença de cristais irregulares contendo manchas escuras, comumente com teores elevados de $\mathrm{Ca}$, além de inclusões de thorita. Nesses zircões, os teores médios de $\mathrm{Hf}$ chegam a 2,6\%, proporcionando razões $\mathrm{Zr} / \mathrm{Hf}$ comparativamente mais baixas (19,7 contra 22,7 e 27,4 dos zircões das rochas anteriores). Nos BSGIA, os zircões são anédricos, corroídos e contêm inclusões de thorita e fluorita. Hf e Y são mais elevados que nos zircões das rochas anteriores e variam de 1,4 a $8,6 \%$ e de 0,3 a $9,7 \%$, respectivamente, atingindo valores médios de 2,9 e 1,4\% e gerando razões $\mathrm{Zr} /$ $\mathrm{Hf}$ médias de 16,5. O conteúdo médio de $\mathrm{Hf}+\mathrm{Y}+\mathrm{Th}+\mathrm{U}$ nos zircões do GAV é crescente das rochas menos evoluídas para as mais evoluídas, enquanto a razão $\mathrm{Zr} / \mathrm{Hf}$ mostra valores decrescentes nesse mesmo sentido (Tabela 3 ).

Nos greisens, os zircões mostram-se igualmente alterados e corroídos, com alguns cristais apresentando bordas de sobrecrescimento bem definidas e enriquecidas em Hf (Figura 10K). Os teores estimados de $\mathrm{Hf}$ desses zircões variam de 1,1 a $7,2 \%$ e os de $\mathrm{Y}$, de 0,3 a $5,1 \%$, com conteúdos médios máximos de 3,2 e 2,5\%, respectivamente (Tabela 3). A somatória de $\mathrm{Hf}+\mathrm{Y}+\mathrm{Th}+\mathrm{U}$ dos zircões dos dois corpos de greisens estudados apresentaram valores médios de 7,1 e $4,1 \%$ e razões $\mathrm{Zr} / \mathrm{Hf}$ médias de 15,2 e 20,2, respectivamente.

Um resumo dos tipos de quartzo dominantes e das razões $\mathrm{Zr} / \mathrm{Hf}$ médias encontradas nos zircões do GAV e greisens associados é mostrado na Tabela 4.

\section{DISCUSSÃO}

\section{Variação morfológico-textural do quartzo e evolução do Granito Antônio Vicente}

Cristais de quartzo das diferentes fácies petrográficas e corpos de greisens estudados por MEV-CL revelaram características morfológicas e texturais distintas que permitiram a identificação de cinco tipos principais. O quartzo magmático (Qz1) teria sido transformado em Qz2 e Qz3 por fluidos hidrotermais que percolaram o GAV. Essas transformações, provavelmente resultantes de processos de alteração, dissolução e recristalização, são mais evidentes nas rochas mais evoluídas (BSGA e BSGIA). Exemplos semelhantes foram observados em cristais de quartzo do granito do Rift Continental de Oslo, Noruega (Larsen, Jacamon, Kronz, 2009). Rusk e Reed (2002) admitem que manchas irregulares de quartzo cinza (Qz2 daquele trabalho) dispersas em quartzo luminescente (Qz1 daquele trabalho), comuns em veios de quartzo-molibidenita do depósito de cobre pórfiro de Butte, Montana, Estados Unidos, seriam formadas pela corrosão do Qz1 ao longo de microfraturas, seguidas da precipitação do Qz2 nas cavidades de corrosão. O Qz4 só foi identificado nas rochas mais evoluídas 

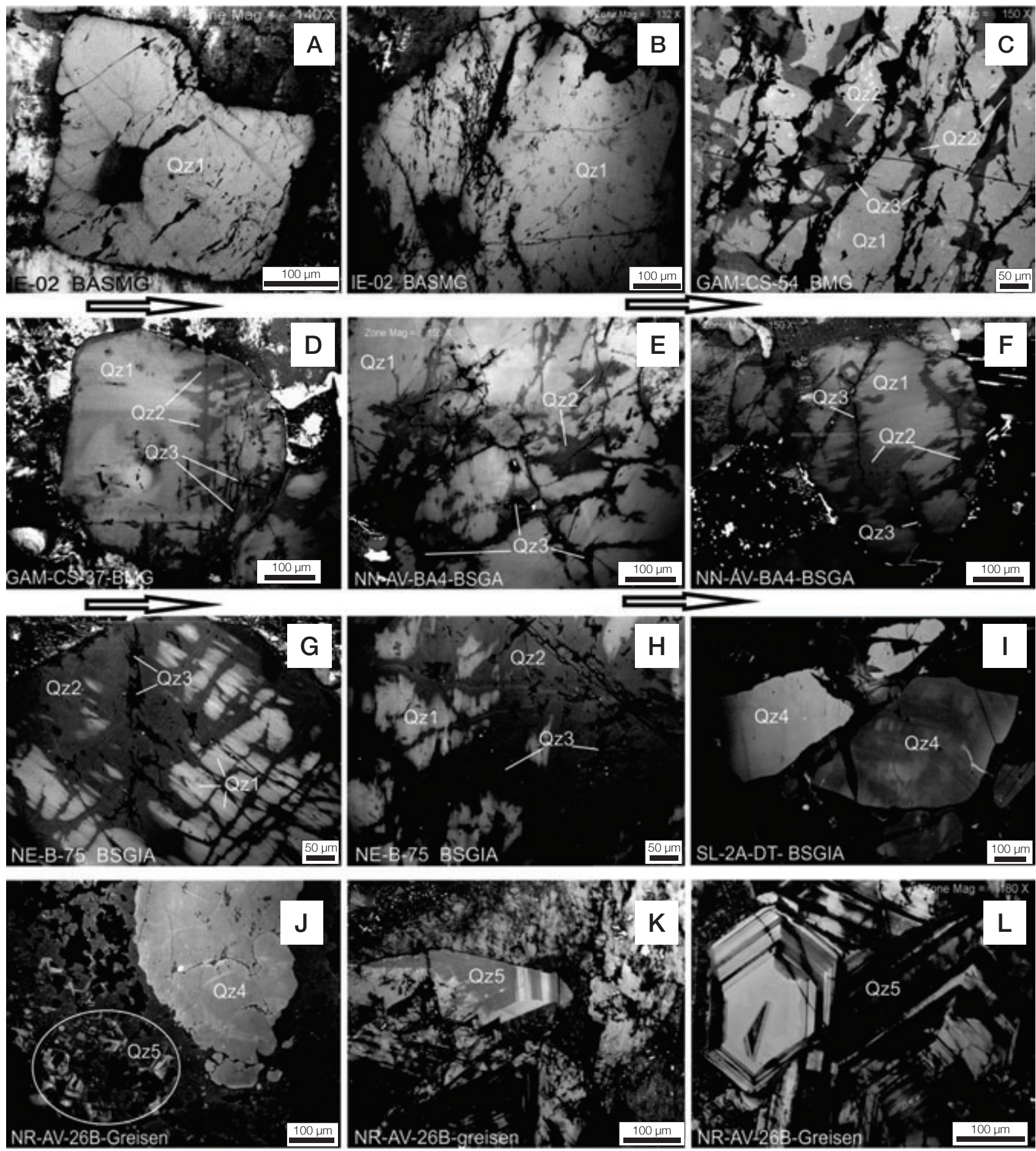

BASMG: biotita-anfibólio sienogranito a monzogranito; BMG: biotita monzogranito; BSG: biotita sienogranito; BSGA: biotita sienogranito alterado; BSGIA: biotita sienogranito intensamente alterado.

Figura 8. Imagens de microscopia eletrônica de varredura - catodoluminescência (MEV-CL) mostrando a evolução dos cristais de quartzo do Granito Antônio Vicente em termos de alteração e fácies petrográficas (setas). (A e B) cristais de quartzo magmático fraturados e com forte luminescência (Qz1); (C-F) quartzo cinza escuro pouco luminescente formando manchas irregulares (Qz2) sobre o Qz1; quartzo preto (Qz3) preenche fraturas e secciona os anteriores; (G e H) Qz2 desenvolve-se com maior intensidade, resultando em pequenas "ilhas" de Qz1; (I e J) cristais de quartzo pouco fraturados (Qz4) e aparecimento de finos agregados de cristais (círculo branco) de quartzo zonados (Qz5); (K) cristais euédricos e zonados de Qz5 preenchendo cavidades; (L) agregado de cristais euédricos, zonados e bem desenvolvidos de Qz5. 
e alteradas do GAV e em corpos de greisens associados. Sua presença parece marcar o início do processo de greisenização. Nos greisens, predominam cristais de quartzo euédricos, com zoneamentos de intensidades diferentes, em um típico padrão hidrotermal (Qz5). Os diferentes tipos e a sequência de transformação dos cristais de quartzo com a evolução e alteração do GAV, além do quartzo predominante nos greisens, estão representados na Figura 8.

\section{Zircão como marcador da evolução do Granito Antônio Vicente}

Zircões do GAV variam morfológica e composicionalmente de acordo com suas fácies petrográficas hospedeiras. Nos
BASMG, são dominantemente euédricos a subédricos, pouco fraturados e corroídos, mostram conteúdos médios de Hf $<2,0 \%$ e as mais elevadas razões $\mathrm{Zr} / \mathrm{Hf}$. Nos BMG e BSGA, os cristais de zircão são subédricos a anédricos fraturados, apresentam conteúdos médios de Hf mais elevados e razões $\mathrm{Zr} / \mathrm{Hf}$ comparativamente mais baixas. Zircões das rochas mais evoluídas e intensamente alteradas (BSGIA) são dominantemente anédricos, corroídos e com frequentes inclusões de thorita e fluorita. Seus conteúdos médios de $\mathrm{Hf}$ chegam a 8,6\% (não mostrado), e suas razões Zr/Hf são inferiores a dos zircões das rochas anteriores (Tabela 3 ).

Nos greisens, os cristais de zircão mostram-se igualmente alterados e apresentam, comumente, bordas de sobrecrescimento corroídas e bem definidas que se destacam do zircão
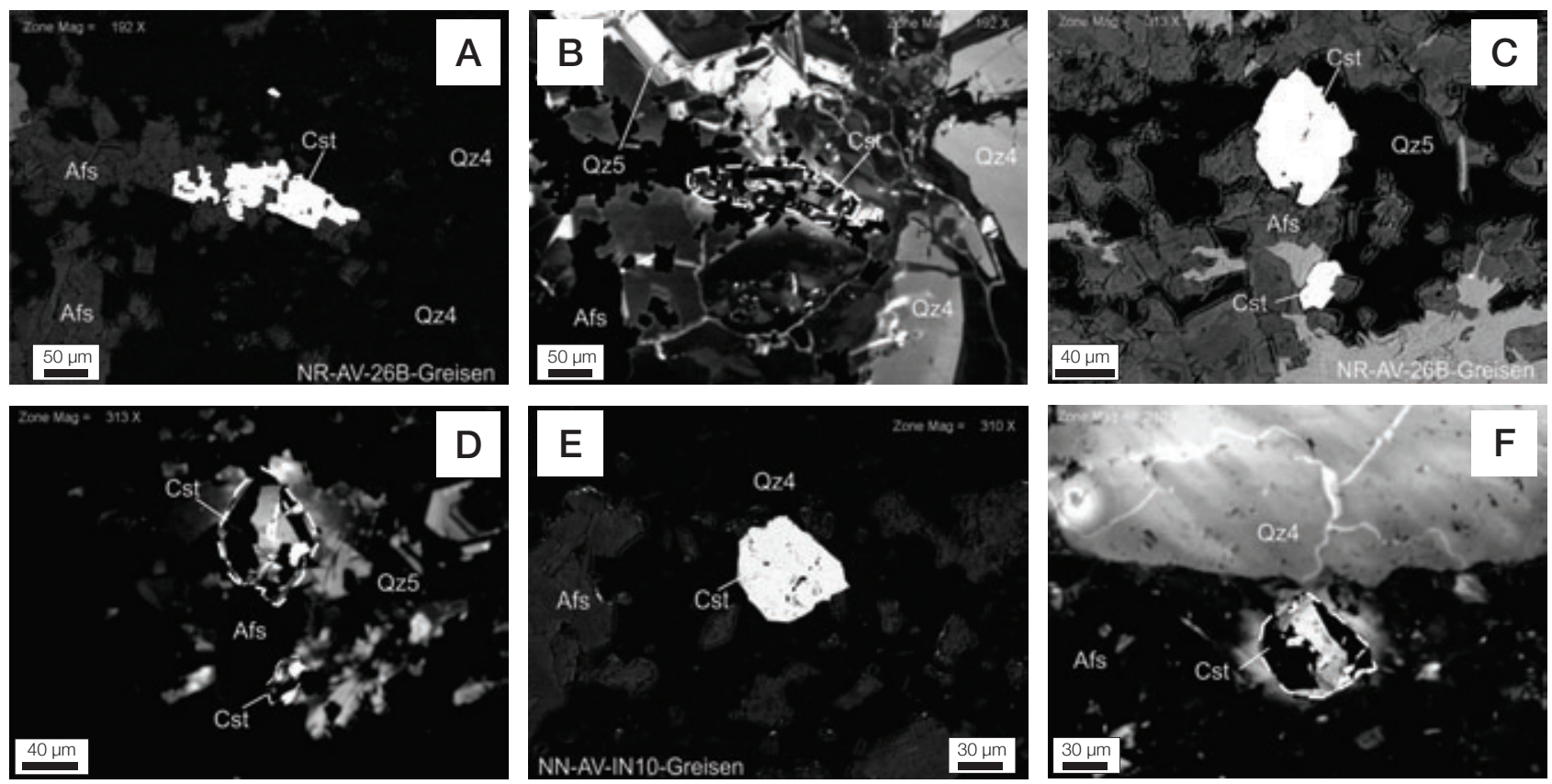

Afs: feldspato alcalino.

Figura 9. Imagens de microscopia eletrônica de varredura - elétrons retroespalhados (MEV-ERE) (A, C, E) e catodoluminescência (CL) (B, D, F) de cristais de cassiterita (Cst) preenchendo cavidades em cristais de Qz4 e Qz5 em greisens do Granito Antônio Vicente.

Tabela 3. Tabela resumida com os dados semiquantitativos médios das 450 análises de zircão (\% em peso) do Granito Antônio Vicente e greisens associados obtidos por Energy Dispersive Spectrometry (EDS).

\begin{tabular}{|c|c|c|c|c|c|c|c|c|c|c|c|c|}
\hline Granito & Fácies & Amostras & 0 & $\mathrm{Si}$ & $\mathrm{Ca}$ & $Y$ & $\mathrm{Zr}$ & $\mathrm{Hf}$ & Th & U & $\mathrm{Zr} / \mathrm{Hf}$ & $\Sigma$ \\
\hline \multirow[t]{7}{*}{ Antônio Vicente } & BASMG & IE-02 (76) & 27,6 & 12,7 & 0,2 & 0,8 & 52,1 & 1,9 & 0,2 & 0,2 & 27,4 & 3,1 \\
\hline & BMG & GAMCS54 (38) & 28,9 & 12,3 & 0,6 & 1,2 & 49,9 & 2,2 & 0,3 & 0,4 & 22,7 & 4,1 \\
\hline & BSGA & AVBA4 (96) & 27,4 & 12,6 & 0,9 & 0,9 & 51,2 & 2,6 & 0,2 & 0,5 & 19,7 & 4,2 \\
\hline & BSGIA & NEB75 (70) & 29,8 & 12,3 & 0,9 & 1,4 & 47,8 & 2,9 & 0,2 & 0,8 & 16,5 & 5,3 \\
\hline & Greisen 1 & AVIN10 (92) & 27,9 & 11,5 & 0,5 & 2,5 & 48,5 & 3,2 & 0,9 & 0,5 & 15,2 & 7,1 \\
\hline & Greisen 2 & NRAV26B (78) & 28,5 & 12,6 & 0,4 & 1,1 & 50,4 & 2,5 & 0,1 & 0,4 & 20,2 & 4,1 \\
\hline & & Média & 28,4 & 12,3 & 0,6 & 1,3 & 50,0 & 2,6 & 0,3 & 0,5 & 20,3 & 4,7 \\
\hline
\end{tabular}

$\Sigma$ = somatória $\mathrm{Hf}+\mathrm{Y}+\mathrm{Th}+\mathrm{U}$. Número de análises de EDS entre parênteses. BASMG: biotita-anfibólio sienogranito a monzogranito; BMG: biotita monzogranito; BSGA: biotita sienogranito alterado; BSGIA: biotita sienogranito intensamente alterado. 

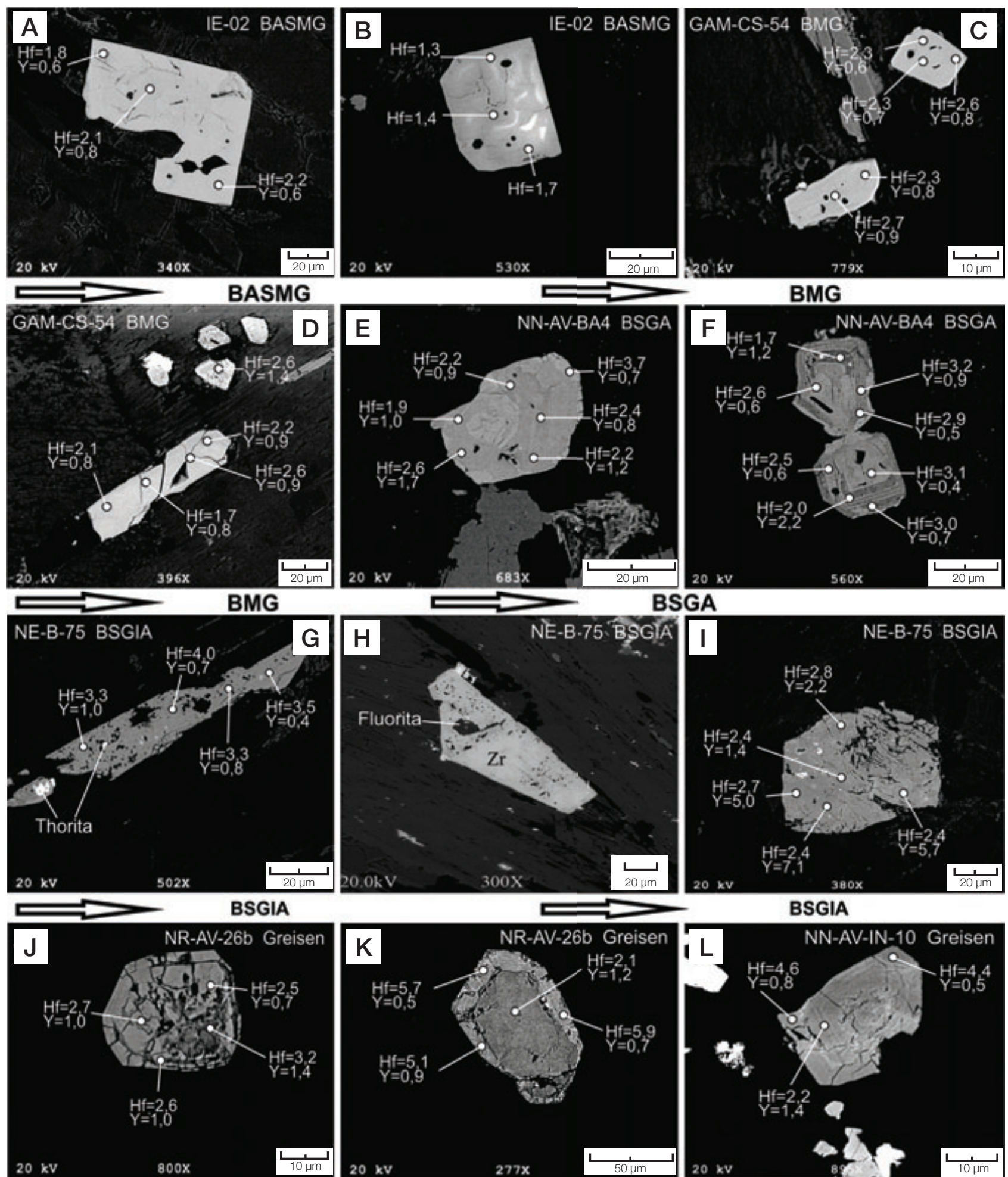

SGA
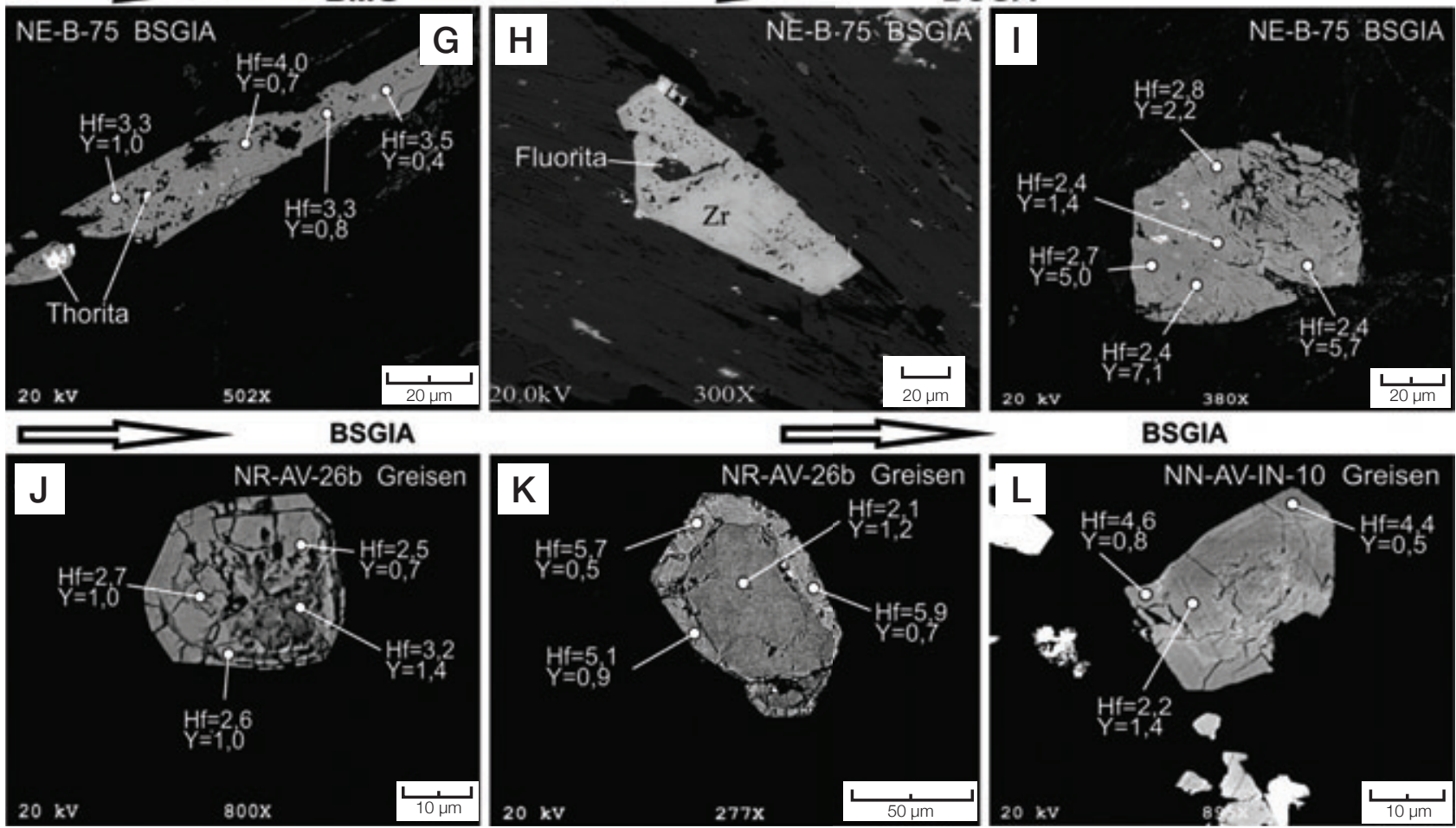

$20 \mathrm{kV}$

$277 x$

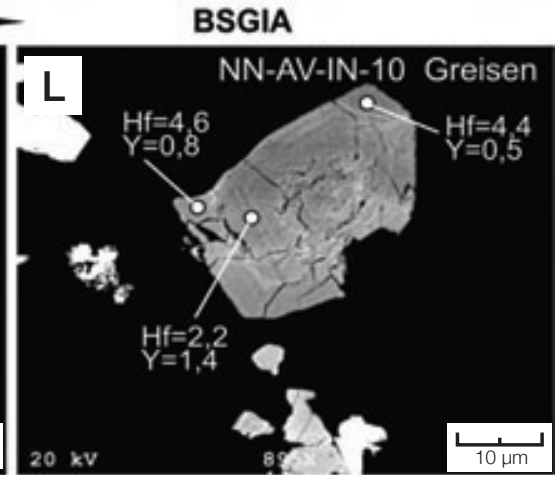

BASMG: biotita-anfibólio sienogranito a monzogranito; BMG: biotita monzogranito; BSGA: biotita sienogranito alterado; BSGIA: biotita sienogranito intensamente alterado.

Figura 10. (A-L) imagens de microscopia eletrônica de varredura - elétrons retroespalhados (MEV-ERE) mostrando a evolução morfológica de zircão do Granito Antônio Vicente e seus conteúdos de Hf e Y (\% em peso), obtidos por Energy Dispersive Spectrometry (EDS). Em (K) destaque para a borda mais clara e enriquecida em Hf em relação ao núcleo. 
Tabela 4. Tipos de quartzo e razões $\mathrm{Zr} / \mathrm{Hf}$ médias estimadas dos zircões estudados.

\begin{tabular}{|c|c|c|c|c|}
\hline Fácies & Amostras & Descrição dos cristais de quartzo & Quartzo dominante & $\begin{array}{l}\mathrm{Zr} / \mathrm{Hf} \\
\text { Zircão }\end{array}$ \\
\hline BASMG & IE-02 & Anédricos a subédricos, fraturados, luminescentes & Qz1 & 27,4 \\
\hline BMG & GAMCS4 & $\begin{array}{l}\text { Anédricos a subédricos, fraturados, luminescentes e parcialmente } \\
\text { alterados }\end{array}$ & Qz1>Qz & 22,7 \\
\hline BSGA & AVBA4 & Anédricos, fraturados, acinzentados e luminescentes & Qz1, Qz2, Qz3 & 19,7 \\
\hline BSGIA & NEB75 & $\begin{array}{l}\text { Anédricos, acinzentados, pouco luminescentes; Aparecimento de } \\
\text { cristais médios a grossos pouco fraturados e com luminescência } \\
\text { variável (transição do estágio magmático para o hidrotermal) }\end{array}$ & $\begin{array}{c}\text { Qz2+Qz3>Qz1; } \\
\text { Qz4 }\end{array}$ & 16,5 \\
\hline Greisens & $\begin{array}{l}\text { AVIN-10 } \\
\quad e \\
\text { NRAV-26B }\end{array}$ & $\begin{array}{l}\text { Euédricos, pouco fraturados, exibindo intensidade variável de CL e } \\
\text { padrão cíclico de zoneamento (quartzo hidrotermal) }\end{array}$ & Qz5>Qz4 & $\begin{array}{c}15,2 \\
e \\
20,2\end{array}$ \\
\hline
\end{tabular}

Qz1, Qz2, Qz3, Qz4 e Qz5: conforme explicitado na Figura 7. BASMG: biotita-anfibólio sienogranito a monzogranito; BMG: biotita monzogranito; BSGA: biotita sienogranito alterado; BSGIA: biotita sienogranito intensamente alterado.

magmático inicialmente formado. Os teores médios de $\mathrm{Hf}$ nessas bordas são elevados ( 6,0\%; Figura $10 \mathrm{~K})$, proporcionando razão $\mathrm{Zr} / \mathrm{Hf}$ média de 9,7 (não mostrada). Tais sobrecrescimentos assemelham-se aos zircões tardios descritos por Wang, Griffin e Chen (2010). Segundo esses autores, zircões tardios e, principalmente, os hidrotermais, exibem zoneamento oscilatório, altos conteúdos de Hf, Th e U e geralmente acompanham minerais tardios como k-feldspato e quartzo. Em rochas graníticas podem ocorrer como grãos individuais, juntamente com zircões formados precocemente, ou na forma de sobrecrescimentos coroando zircões precocemente formados (Figura 3 do trabalho citado).

\section{Mineralização do Granito Antônio Vicente}

Finos cristais de cassiterita aparecem associados ou inclusos em cristais de Qz4 e Qz5. O primeiro é comum nas rochas mais evoluídas e alteradas do GAV e considerado como marcador do início do processo de greisenização. O segundo, de origem claramente hidrotermal, domina nos corpos de greisens. Cristais de zircão dos BSGIA e greisens associados, ambos mineralizados em cassiterita, mostraramse enriquecidos em $\mathrm{Hf}$ e com as mais baixas razões $\mathrm{Zr} / \mathrm{Hf}$ quando comparados aos zircões das outras rochas do GAV, indicando que tais características geoquímicas podem ser utilizadas preliminarmente como guia prospectivo de granitos e greisens estaníferos. Os dados obtidos em quartzo e zircão por meio de MEV-CL-EDS estão de acordo com as observações de Teixeira (1999) e Teixeira et al. (2005), que admitem as rochas mais evoluídas e corpos de greisens como hospedeiros da mineralização de Sn do GAV.

\section{CONCLUSÕES}

O GAV mostra evolução magmática representada por várias fácies petrográficas e encontra-se alterado hidrotermalmente em diferentes intensidades. Está mineralizado em Sn em suas rochas mais evoluídas e alteradas e em corpos de greisens associados, o que o torna apropriado para a aplicação da metodologia MEV-CL em cristais de quartzo e zircão. Este estudo mostrou que o quartzo foi um excelente marcador da evolução magmática e das alterações impostas pelos processos hidrotermais que atuaram no GAV, sendo distinguidos uma geração magmática (Qz1) e quatro tipos hidrotermais (Qz2, Qz3, Qz4 e Qz5). As imagens de CL indicam que a mineralização estanífera desse granito está presente nas suas rochas mais evoluídas e alteradas hidrotermalmente e em corpos de greisens associados, onde foram identificados finos cristais de cassiterita associados ou inclusos em cristais de Qz4 e Qz5, considerados de origem hidrotermal. O comportamento do $\mathrm{Hf}$ e as razões $\mathrm{Zr} / \mathrm{Hf}$ em zircões graníticos podem ser utilizadas como traçadores geoquímicos no estudo da origem e ambiente de cristalização de seu magma hospedeiro (Belousova et al., 2002; Wang, Griffin, Chen, 2010), além de atuar como ferramenta prospectiva preliminar para granitos especializados (Lamarão et al., 2007, 2010, 2012 e artigo em preparação). No GAV, os zircões com os mais elevados conteúdos de $\mathrm{Hf}$ e as mais baixas razões $\mathrm{Zr} / \mathrm{Hf}$ pertencem às rochas mais evoluídas e alteradas hidrotermalmente e aos corpos de greisens, ambos portadores de mineralizações de Sn, indicando que essas características podem ser utilizadas na avaliação preliminar do potencial metalogenético de granitos estaníferos. O trabalho apresentado mostrou que a metodologia MEV-CL em cristais de quartzo e zircão pode ser utilizada como ferramenta complementar em estudos petrológicos e metalogenéticos.

\section{AGRADECIMENTOS}

Ao Instituto de Geociências da Universidade Federal do Pará - UFPA e ao Grupo de Pesquisa Petrologia de 
Granitoides (GPPG) da UFPA. Este trabalho é uma contribuição ao Instituto de Geociências da Amazônia - GEOCIAM (programa INCT - CNPq/MCT/FAPESPA - processo 573733/2008-2).

\section{REFERÊNCIAS}

ALMEIDA J. A. C.; DALL'AGNOL, R.; DIAS S. B.; ALTHOFF F, J. Origin of the Archean leucogranodioritegranite suites: evidence from the Rio Maria terrane and implications for granite magmatismo in the Archean. Lithos, v. 120, p. 235-257, 2010.

ALMEIDA, J. A. C.; OLIVEIRA, M. A.; DALL'AGNOL, R.; ALTHOFF F. J.; BORGES R. M. K. Relatório de mapeamento geológico na escala 1:100.000 da Folha Marajoara (SB-22-z-C v). Programa Geobrasil, CPRM Serviço Geológico do Brasil, 2008, 147 p.

ALMEIDA J. A. C.; DALL'AGNOL, R.; OLIVEIRA, M.A.; MACAMBIRA, M. J. B.; PIMENTEL, M. M.; RÄMÖ, O. T.; GUIMARÃES, F. V.; LEITE, A. A. S. Zircon geochronology and geochemistry of the TTG suites of the Rio Maria Granite-Greenstone terrane: Implications for the growth of the Archean crust of the Carajás Province, Brazil. Precambrian Research, v. 187, p. 201-221, 2011.

ALTHOFF, F. J.; BARBEY, P.; BOULLIER, A. M. 2.8 3.0 Ga plutonism and deformation in the SE Amazonian craton: the Archaean granitoids of Marajoara (Carajás Mineral Province, Brazil). Precambrian Research, v. 104, p. 187-206, 2000.

ARAÚJO, O. J. B.; MACAMBIRA, E. M. B.; VALE A. G.; OLIVEIRA, J. R.; SILVA NETO, C. S.; COSTA E. J. S.; SANTOS, A.; PENA FILHO, J. I. C.; NEVES, A. P.; JORGE JOÃO, X. S.; COSTA J. B. S. Primeira integração das investigações geológicas do Programa Grande Carajás na região SSE do Estado do Pará. In: SIMPÓSIO DE GEOLOGIA DA AMAZÔNIA, 4., 1994. Belém. Boletim de Resumos... Belém: SBG, 1994. p. 299-301.

ARAÚJO, O. J. B.; MAIA, R. G. N.; JORGE JOÃO, X. S.; COSTA J. B. S. A megaestruturação arqueana da folha Serra dos Carajás. In: CONGRESSO LATINO AMERICANO DE GEOLOGIA, 7., 1988. Belém. Anais... Belém: SBG, 1988. v.1, p. 324-333.

BELOUSOVA, E. A.; GRIFFIN, W. L.; O' REALLY, S. Y.; FISHER, N. Y. Trace elements in zircon: relationship to source rock type. Contribution to Mineralogy and Petrology, v. 143, p. 602-622, 2002.
BOGGS, S. JR.; KRINSLEY, D. H.; GOLES, G. G.; SEYEDOLALI, A.; DYPVIK, H. Identification of shocked quartz by scanning cathodoluminescence imaging. Meteoritics e Planetary Science, v. 36, p. 783-791, 2001.

BOtTINGA, Y.; KUDO, A.; WEILL, D. Some observations on oscillatory zoning and crystallization of magmatic plagioclase. American Mineralogist, v. 51, p. 792-806, 1966.

BREITER, K.; FORSTER, H. J.; SKODA, R. Extreme $\mathrm{P}-, \mathrm{Bi}-, \mathrm{Nb}-, \mathrm{Sc}-, \mathrm{U}-$ and F-rich zircon from fractionated perphosphorous granites: The peraluminous Podlesí granite system, Czech Republic. Lithos, v. 88, p. 15-34, 2005.

BREITER, K.; MÜLLER, A. Evolution of rare-metal granitic magmas documented by quartz chemistry. European Journal of Mineralogy, v. 21, p. 335-346, 2009.

CHANG, Z.; MEINERT, L. D. The magmatic-hydrothermal transition: evidence from quartz phenocrysts textures and endoskarn abundance in $\mathrm{Cu}-\mathrm{Zn}$ skarns at the Empire Mine, USA. Geochemical Geology, v. 210, p. 149-171, 2004.

COSTA, J. B. S.; ARAÚJO, O. J. B.; SANTOS, A.; JORGE JOÃO, X.,S.; MACAMBIRA, M. J. B.; LAFON, J. M. A Província Mineral de Carajás: Aspectos Tectono-Estruturais, Estratigráficos e Geocronológicos. Boletim do Museu Paraense Emílio Goeldi, Série Ciências da Terra, v. 7, p. 199-235, 1995.

CPRM/DNPM. Projeto Especial Mapas de Recursos Minerais, de Solo e de Vegetação para a Área do Projeto Grande Carajás - Sub Programa Mapas metalogenéticos e de Previsão de Recursos Minerais. Folha São Felix do Xingu-SB-22-Y-B. CPRM, Superintendência Regional de Belém (Relatório Final), 1997.

DALL'AGNOL, R.; TEIXEIRA, N. P.; RÄMO, O. T.; MOURA, C. A. V.; MACAMBIRA, M. J. B.; OLIVEIRA, D. C. Petrogenesis of the Paleoproterozoic rapakivi A-type granites of the Archean Carajás metallogenic province, Brazil. Lithos, v. 80, p. 101-129, 2005.

D'LEMOS, R. S.; KEARSLEY, A. T.; PEMBROKE, J. W.; WATT, G. R.; WRIGHT, P. Complex quartz growth histories in granite revealed by scanning cathodoluminescence techniques. Geological Magazine, v. 134, n. 4, p. 549-552, 1997.

FEIO, G. R. L. Magmatismo Granitóide Arqueano da área de Canaã dos Carajás: Implicações para a evolução crustal da Província Carajás. 2011. Tese (Doutorado) - Instituto de Geociências, Universidade Federal do Pará, Belém. 
FERNANDES, C. M. D.; LAMARÃO, C. N.; TEIXEIRA, N. P. O vulcanismo bimodal do tipo Uatumã da região de São Félix do Xingu (PA), Província Mineral de Carajás. Revista Brasileira de Geociências, v. 36, n. 3, p. 523-534, 2006.

FERNANDES, C. M. D. Estratigrafia e Petrogênese das Seqüências Vulcânicas Paleoproterozóicas na região de São Félix do Xingu (Pa), Província Mineral de Carajás. 2009. 190p. Tese (Doutorado) - Instituto de Geociências, Universidade de São Paulo, São Paulo.

FOWLER, A.; PROKOPH, A.; STERN, R.; DUPUIS, C. Organization of oscillatory zoning in zircon: Analysis, scaling geochemistry, and model of a zircon from Kipawa, Quebec, Canada. Geochimica et Cosmochimica Acta, v. 66, p. 311-328, 2002.

GUIMARÃES, F. V. Geologia, petrografia e geoquímica do Trondhjemito Mogno e rochas arqueanas associadas, Terreno Granito-Greenstone de Rio Maria-SE do Pará. 2009. Dissertação (Mestrado) - Instituto de Geociências, Universidade Federal do Pará, Belém.

HANCHAR, J. M; MILLER, C. F. Zircon zonation patterns as revealed by cathodoluminescence and backscattered electron images: implications for interpretation of complex crustal histories. Chemical Geology, v. 110, p. 1-13, 1993

HANCHAR, M.; HUDNICK, R. L. The application of cathodoluminescence and back-scattered electron imaging to dating zircons from lower crustal xenoliths. Lithos, v. 36, p. 289-303, 1995.

HEAMAN, L. M.; BOWINS, R.; CROCKET, J. The chemical composition of igneous zircon suites: Implications for geochemical tracer studies. Geochimica et Cosmochimica Acta, v. 54, p. 1597-1607, 1990.

HOFFMAN, M. Growth history of zircon crystals in coarse-grained granite, vinalhaven intrusion, coastal. In: ANNUAL KECK SYMPOSIUM, 20., 2007. Wooster, Ohio. Anais... p. 124-129.

HOGAN, J. P. Monomineralic glomerocrysts: Textural evidence for mineral resorption during crystallization of igneous rocks. Journal of Geology, v. 101, p. 531-540, 1993.

HOSKIN, P. W. O.; IRELAND, T. R. Rare earth element chemistry of zircon and its use as a provenance indicator. Geology, v. 28, p. 627-630, 2000.

HUHN, S. R. B.; SANTOS, A. B. S.; AMARAL, A. F.; LEDSHAM, E. J.; GOUVEIA, J. L.; MARTINS, L. B.
P.; MONTALVÃO, R. M. G.; COSTA, V. G. O Terreno Granito-Greenstone da região de Rio Maria - Sul do Pará. In: CONGRESSO BRASILEIRO DE GEOLOGIA, 35., 1988. Belém. Anais... Belém: SBG: 1988. v. 3, p. 1438-1453.

JACAMON, F.; LARSEN, R. B. Trace element evolution of quartz in the charnockitic Kleivan granite, SWNorway:The Ge/Ti ratio of quartz as an index of igneous differentiation. Lithos, v. 102, p. 281-291, 2009.

JULIANI, C.; FERNANDES, C. M. D. Well-preserved late paleoproterozoic volcanic centers in the São Felix do Xingu region, Amazonian Craton, Brazil. Journal of Volcanology and Geothermal Research, v. 191, n. 3-4, p. 167-79, 2010.

KEMPE, U.; GRUNER, T.; RENNO, A. D.; WOLF, D. Hf-rich zircon in rare-metal bearing granites: Magmatic or metasomatic origin? In: PAPUNEN, H. (Ed.). Mineral Deposits: Research and Exploration. Rotterdam: Balkema, 1997. p. 643-646.

KEMPE, U.; GRUNER, T.; RENNO, A. D.; WOLF, D.; RENÉ, M. Discussion on Wang et al. (2000) "Chemistry of Hf-rich zircons from the Laoshan I- and A-type granites, Eastern China”. Mineralogical Magazine, v. 64, p. 867877, 2004.

LAGLER, B. 2011. Geologia e Geoquímica das sequências vulcânicas paleoproterozóicas do Grupo Uatumã na região de São Félix do Xingu (PA), Cráton Amazônico. 2011.Dissertação (Mestrado), Instituto de Geociências, Universidade de São Paulo, São Paulo.

LAMARÃO, C. N.; DALL'AGNOL, R.; LAFON, J. M.; LIMA, E. F. Geology, geochemistry and $\mathrm{Pb}-\mathrm{Pb}$ zircon geochronology of the Paleoproterozoic magmatism of Vila Riozinho, Tapajós Gold Province, Amazonian craton, Brazil. Precambrian Research, v. 119, p. 189-223, 2002.

LAMARÃO, C. N.; DALL'AGNOL, R.; PIMENTEL, M. M. Nd Isotopic composition of Paleoproterozoic volcanic and granitoid rocks of Vila Riozinho: Implications for the crustal evolution of the Tapajós Gold Province, Amazon craton. Journal of South American Earth Sciences, v. 18, p. 277-292, 2005.

LAMARÃO, C. N.; DALL'AGNOL, R.; SOLEDADE, G. L.; SILVA J. S. Variações composicionais de zircão em granitos anorogênicos proterozóicos do Cráton Amazônico: implicações metalogenéticas. Revista Brasileira de Geociências, v. 37, p. 693-704, 2007. 
LAMARÃO, C. N.; DALL'AGNOL, R.; SILVA, J. S.; SOLEDADE, G. L. Morphological and compositional variation in zircons of tin-specialized Paleoproterozoic A-type granites of the Amazonian craton: Metallogenic implications. In: INTERNATIONAL CONFERENCE ON A-TYPE GRANITES AND RELATED ROCKS THOUGH TIME, IGCP-510, 2010, Helsinki-Finland. Abstract Volume... Helsinki: O. Tapani Ramo, Sari Lukkari, Aku Heinonen (eds.), Helsinki University-Department of Geosciences and Geography. Helsinki University Print. 2010... p. 68-70.

LAMARÃO, C. N.; SILVA, J. S.; BORGES, R. M. K.; DALL'AGNOL, R. Variação morfológica e composicional de zircão e suas implicações metalogenéticas: o exemplo das Suítes Jamon, Velho Guilherme e Serra dos Carajás, Cráton Amazônico. Submetido à Revista Brasileira de Geociências, (em preparação).

LAMARÃO, C. N.; PINHO, S. C. C., JUNIOR, A. L. P., TORO, M. A. G. Mineralogy and geochemistry of the Paleoproterozoic, tin-mineralized Bom Jardim Granite of the Velho Guilherme Suite, eastern Amazonian Craton. Journal of South American Earth Science, v. 38, p. 159173, 2012.

LAMARÃO, C. N.; MARQUES, G. T. MEV-CL em zircões de traquitos da Província Aurífera do Tapajós: Implicações quanto à origem e extensão da Formação Vila Riozinho. (em preparação).

LANDTWING, M. R.; PETTKE, T. Relationships between SEM-cathodoluminescence response and trace-element composition of hydrothermal vein quartz. American Mineralogist, v. 90, p. 122-131, 2005.

LARSEN, R. B.; JACAMON F.; KRONZ, A. Trace element chemistry and textures of quartz during the magmatic hydrotermal transition of Oslo Rift granites. Mineralogical Magazine, v. 37, n. 4, p. 691-707, 2009.

LEITE, A. A .S.; DALL'AGNOL, R.; MACAMBIRA, M. J. B.; ALTHOFF, F. J. Geologia e geocronologia dos granitóides arqueanos da região de Xinguara (PA) e suas implicações na evolução do Terreno Granito-Greenstone de Rio Maria. Revista Brasileira de Geociências, v. 34, p. 447-458, 2004.

LOOMIS, T. P.; WELBER, P. W. Crystallization processes in the Rocky Hill granodiorite Pluton, California: An interpretation based on compositional zoning of plagioclase. Contribution to Mineralogy and Petrology, v. 8, n. 14, p. 230-239, 1982.
MACAMBIRA, E. M. B.; VALE, A. G. Programa de Levantamentos Geológicos Básicos do Brasil, Programa Grande Carajás, Folha SB-22-Y-B, São Félix do Xingú, Estado do Pará-Belém, convênio DNPM/CPRM, 1997, 344 p.

MACAMBIRA, E. M. B. e TASSINARI, C. C. G-Estudos Sm/Nd no Complexo Máfico-Ultramáfico da Serra da Onça - Sul do Pará: Implicações Geocronológicas e Geológicas e Geotectônicas. In: CONGRESSO BRASILEIRO DE GEOLOGIA, 40., 1998. Belo Horizonte. Anais... Belo Horizonte: SBG, 1998. p. 463.

MACAMBIRA, E. M. B.; FERREIRA-FILHO, C. F. Fracionamento magmático dos corpos máficosultramáficos da Suíte Intrusiva Cateté - Sul do Pará. In: KLEIN, E. L.; VASQUEZ, M. L.; COSTA, L. T. R. (Orgs.). Contribuições à Geologia da Amazônia, SBG, Núcleo Norte, 2002, v. 3, p. 105-114.

MARSHALL, D. J. Cathodoluminescence of geological materials. Winchester/Mass: Allen and Unwin, 1988.

MÜLLER, A.; SELTAMAN, R.; BEHR, H-J. Application of cathodoluminescence to magmatic quartz in a tin granite-case study from the Schellerhau granite Complex, Eastern Erzgebirge, Germany. Mineralium Deposita, v. 35, p. 169-18, 2000.

MÜLLER, A.; KRONZ, A.; BREITER, K. Trace elements and growth pattern in quartz: a fingerprint of the evolution of the subvolcanic Podlesí Granite System (Krusné Hory, Czech Republic). Bulletin of Czech Geological Survey, v. 77, p. 135-145, 2002.

MÜLLER, A.; RENÉ, M.; BEHR, H. J.; KRONZ, A. Trace elements and cathodoluminescence in igneous quartz in topaz granites from the Hub Stock (Slavkovský Les Mts., Czech republic). Mineralogy and Petrology, v. 79, p. 167-191, 2003.

MÜLLER, A.; BREITER, K.; SELTMANN, R; PÉCSKAY, Z. Quartz and feldspar zoning in the eastern Erzgebirge volcano-plutonic complex (Germany, Czech Republic): evidence of multiple magma mixing. Lithos, v. 80, p. 201227, 2005.

OLIVEIRA, M. A.; DALL'AGNOL, R.; ALTHOFF, F. J.; LEITE, A. A. S. Mesoarchean sanukitoid rocks of the Rio Maria Granite-Greenstone Terrane, Amazonian craton, Brazil. Journal of South American Earth Sciences, v. 27, p. 146-160, 2009.

PAIVA JR., A. L.; LAMARÃO, C. N.; LIMA, P. H. A. Geologia, petrografia e geoquímica do batólito Seringa, 
Província Mineral de Carajás, SSE do Pará. Revista Brasileira de Geociências, v. 41, n. 2, p. 185-202, 2011.

PATERSON B. A.; STEPHENS, W. E.; ROGERS, G.; WILLIAMS, I. S.; HINTON, R. W.; HERD, D. A. The nature of zircon inheritance in two granite plutons. Transactions of Royal Society of Edinburgh Earth Science, v. 83, p. 459-471, 1992.

PEARCE, J. A.; HARRIS, N. B. W.; TINDLE, A. G. Trace element discrimination diagrams for the tectonic interpretation of granitic rocks. Journal of Petrology, v. 25, p. 956-983, 1984.

PINHO, S. C. C. Petrografia e geocronologia da borda ENE do Granito Serra da Queimada e da borda SE do Granito Bom Jardim, Província Estanífera do Sul do Pará. 2005. Trabalho de Conclusão de Curso. Centro de Geociências, Universidade Federal do Pará, Belém.

PINHO, S. C. C.; FERNANDES, C. M. D.; TEIXEIRA, N. P.; PAIVA JR., A. L.; CRUZ, V. L.; LAMARÃO, C. N.; MOURA, C. A. V. O magmatismo paleoproterozóico da região de São Félix do Xingu, Província Estanífera do sul do Pará: petrografia e geocronologia. Revista Brasileira de Geociências, v. 36, n. 4, p. 724-732, 2006.

PUPIN, J. P. Granite genesis related to geodynamics from Hf-Y in zircon. Transactions of Royal Society of Edinburgh Earth Science, v. 91, p. 245-256, 2000.

RUSK, B. G.; REED, M. H. Scanning electron microscopecathodoluminescence analysis of quartz reveals complex growth histories in veins from the Butte porphyry copper deposit, Montana. Geology, v. 30, n. 8, p. 727-730, 2002.

RUSK, B. G.; REED, M. H.; DILLES, J. H.; KENTI, A. J. R. Intensity of quartz cathodoluminescence and traceelement content in quartz from the porphyry copper deposit at Butte, Montana. American Mineralogist, v. 91, p. 1300-1312, 2006.

RUSK, B. G; LOWERS, H. A.; REED, M. H. Trace elements in hydrothermal quartz: Relationships to cathodoluminescent textures and insights into vein formation. Geology, v. 36, n. 7, p. 547-550, 2008.

SLABY, E.; GÖTZE, J.; WÖRNER, G.; SIMON, K.; WRZALIK, R.; SMIGIESKI, M. K-feldspar phenocrysts in microgranular magmatic enclaves: a cathodoluminescence and geochemical study of crystal growth as a marker of magma mingling dynamics. Lithos, v. 105, p. 85-97, 2008.
TASSINARI, C. C. G.; MACAMBIRA, M. J. B. Evolução tectônica do Cráton Amazônico. In: MANTESSONETO, V.; BARTORELLI, A.; CARNEIRO, C. D. R.; BRITO NEVES, B. B. (Eds). Geologia do Continente Sul Americano: Evolução da obra de F.F.M. de Almeida. São Paulo: Beca, 2004. p. 471-486.

TEIXEIRA, N. P.; DALL'AGNOL, R. Geologia e petrografia do Maciço Granítico Antonio Vicente. Região de São Félix do Xingu/PA. Boletim do Museu Paraense Emílio Goeldi, Série Ciência da Terra, v. 3, p. 45-73, 1991.

TEIXEIRA, N. P.; BETTENCOURT, J. S.; MOURA, C. A. V.; DALL'AGNOL, R. $\mathrm{Pb} / \mathrm{Pb}$ and $\mathrm{Sm}-\mathrm{Nd}$ constraints of the Velho Guilherme intrusive suite and volcanic rocks of the Uatumã Group. South-Southeast Pará-Brasil. In: INTERNATIONAL FIELD CONFERENCES, 426 IGCP-PROJECT, September 13-19, 1998, Wisconsin, USA. VanSchmus W.R., Brown B.A., Mudrey M.G.Jr. (Eds.). Anais... Wisconsin: Geological and Natural History Survey, 1998. p.178-180.

TEIXEIRA, N. P. Contribuição ao estudo das rochas granitóides e mineralizações associadas da Suíte intrusiva Velho Guilherme, Província Estanífera do Sul do Pará. 1999. 508 p. Tese (Doutorado). Instituto de Geociências, Universidade de São Paulo, São Paulo.

TEIXEIRA, N. P.; BETTENCOURT, J. S. Velho Guilherme Intrusive Suite, Pará, Brazil: petrogenetic aspects and associated mineralization. In: INTERNATIONAL GEOLOGIC CONGRESS, IGCP-426, 2000. Rio de Janeiro. Abstract volume... Rio de Janeiro: AGC, 2000.

TEIXEIRA, N. P.; BELLO, R. M. S., BETTENCOURT, J. S. Inclusões fluidas do Maciço Granítico Antônio Vicente, Suíte Intrusiva Velho Guilherme, Província Estanífera do Sul do Pará. Revista Brasileira de Geociências, v. 32, n. 1, p. 135-146, 2002.

TEIXEIRA, N. P.; BETTENCOURT, J. S.; MOURA, C. A. V.; DALL'AGNOL, R.; MACAMBIRA, E. B. Archean crustal sources for Paleoproterozoic tin-mineralized granites in the Carajás Province, SSE Pará, Brazil: $\mathrm{Pb}-\mathrm{Pb}$ geochronology and $\mathrm{Nd}$ isotope geochemistry. Precambrian Research, v. 119, p. 257-275, 2002.

TEIXEIRA, N.P.; BETTENCOURT, J. S.; DALL'AGNOL, R.; MOURA, C. A. V.; FERNANDES, C. M. D.; PINHO, S. C. C. Geoquímica dos granitos paleoproterozóicos da Suíte Granítica Velho Guilherme, Província Estanífera do Sul do Pará. Revista Brasileira de Geociências, v. 35, p. 217-226, 2005. 
UHER, P.; BREITER, K.; KLECKA, M.; PIVEC, E. Zircon in highly evolved Hercynian Homolka Granite, Moldanubian Zone, Czech Republich: indicator of magma source and petrogenesis. Geologica Carpathica, v. 49, p. 151-160, 1998.

VASQUEZ, L. V.; ROSA-COSTA, L. R.; SILVA, C. G.; RICCI, P. F.; BARBOSA, J. O.; KLEIN E. L.; LOPES, E. S.; MACAMBIRA, E. B.; CHAVES, C. L.; CARVALHO, J. M.; OLIVEIRA, J. G.; ANJOS, G. C.; SILVA, H. R. Geologia e Recursos Minerais do Estado do Pará: Sistema de Informações Geográficas - SIG: texto explicativo dos mapas Geológico e Tectônico e de Recursos Minerais do Estado do Pará. Vasquez M. L.; Rosa-Costa L. T. (orgs.) Belém, CPRM: 2008. Escala 1:1.000.000.

VAVRA, G.; GEBAUER, D.; SCHMID, R.; COMPSTON, W. Multiple zircon growth and recrystallization during polyphase Late Carboniferous to Triassic metamorphism in granulites of the Ivrea zone (Southern Alps): an ion microprobe (SHRIMP) study. Contribution to Mineralogy and Petrology, v. 122, p. 337-358, 1996.
WANG, R. C.; ZHAO, G. T.; LU, J. J.; CHEN, X. M.; XU, S.J.; WANG, D. Z. Chemistry of Hf zircons from the Laoshan I- and A-type granites, Eastern China. Mineralogical Magazine, v. 64, p. 867-877, 2000.

WANG, X.; GRIFFIN, W. L.; CHEN, J. Hf contents and $\mathrm{Zr} / \mathrm{Hf}$ ratios in granitic zircons. Geochemical Journal, v. 44, p. 65-72, 2010.

WHALEN, J. B.; CURRIE, K. L.; CHAPPELL, B. W. A-type granites: geochemical characteristics, discrimination and petrogenesis. Contribution to Mineralogy and Petrology, v. 95, p. 407-419, 1987.

WHITNEY, D. L.; EVANS, B. W. Abbreviations for names of rock-forming minerals. American Mineralogist, v. 95, p. 185-187, 2010.

WIEBE, R. A.; WARK, D. A.; HAWKINS, D. P. Insights from quartz cathodoluminescence zoning into crystallization of the Vinalhaven granite, coastal Maine. Contribution to Mineralogy and Petrology, v. 154, p. 439-453, 2007. 